\author{
dspace.vutbr.cz
}

\title{
Effect of liquid preheating on high-velocity airblast atomization: From water to crude rapeseed oil
}

\author{
URBÁN, A.; MALÝ, M.; JÓZSA, V.; JEDELSKÝ, J.
}

Experimental Thermal and Fluid Science

2019, vol. 102, April 2019, pp. 137-151

ISSN: 0894-1777

DOI: https://doi.org/10.1016/j.expthermflusci.2018.11.006

Accepted manuscript

(C) 2018. This manuscript version is made available under the CC-BY-NC-ND 4.0 license (http://creativecommons.org/licenses/by-nc-nd/4.0/), doi:

https://doi.org/10.1016/j.expthermflusci.2018.11.006

Final version available from https://www.sciencedirect.com/science/article/pii/s0894177718314377 


\title{
Effect of liquid preheating on high-velocity airblast atomization: from water to crude rapeseed oil
}

\author{
András Urbán ${ }^{\mathrm{a}}$, Milan Malýb, Viktor Józsa ${ }^{\mathrm{a}}$, Jan Jedelskýb \\ a Budapest, University of Technology and Economics, Faculty of Mechanical \\ Engineering, Department of Energy Engineering, 1111 Budapest, Müegyetem rkp. 3., \\ Hungary \\ b Faculty of Mechanical Engineering, Brno University of Technology, Technicka 2896/2, \\ 61669 Brno, Czech Republic
}

\begin{abstract}
Airblast atomization is a suitable model platform to understand atomization physics since the atomizer geometry has an insignificant influence on the spray formation. Besides its theoretical relevance, this configuration is used in several practical applications ranging from healthcare to combustion. Presently, a plain-jet airblast atomizer has been investigated experimentally under atmospheric conditions at various atomizing pressures and liquid preheating temperatures. To cover a wide range of liquids by viscosity and surface tension, water, diesel oil, light heating oil, and crude rapeseed oil were atomized to evaluate the droplet size-velocity correlations when the spray is fully developed. Increasing the temperature of high-viscosity liquids prior to atomization improves the spray characteristics until their kinematic viscosity decreases to a certain value that is newly introduced as a limiting viscosity. Further preheating has a marginal effect on droplet size-velocity plots, and the spray becomes more homogeneous. Several SMDestimating formulae were analyzed and improved to consider the effect of liquid preheating and to extend their range of validity. When the kinematic viscosity exceeded
\end{abstract}


the limiting viscosity, the part containing the Weber number was corrected linearly by the preheating temperature. The coefficient of the Ohnesorge number was corrected by the inverse of the kinematic viscosity, without considering the limiting viscosity. The above results help to correct the $S M D$ of atmospheric measurements to elevated liquid temperatures and to contribute to advanced atomization models for numerical software.

Keywords: airblast atomizer; SMD; PDA; rapeseed oil; light heating oil; preheating 


\section{Nomenclature}

Latin letters

a

$A, B, C, E, F, G, H, I, J, K, L, M$

ALR

$D$

$d, d_{0}$

EFR

ISMD $D_{\text {meas }}$

l

m

$M a$

MFR

$\mathrm{Oh}$

$p_{g}$

$R^{2}$

$R e$

SMD

$S M D_{\text {calc }}$

$t_{p}$

$t_{r}$

$u$

We

Greek symbols

$\mu$

$\rho$

$\sigma$

$v_{l, l i m}$

\section{Abbreviations}

D

GA

LHO

PDA

$\mathrm{RO}$

$\mathrm{ScS}$

W

\section{Subscripts}

a

l

$r$

$x, y, z$
Speed of sound, $\mathrm{m} / \mathrm{s}$

Experimental parameters

Air-to-liquid mass flow ratio, -

Droplet diameter, $\mu \mathrm{m}$

Characteristic size, mm

Energy flux rate, -

Measured integral SMD, $\mu \mathrm{m}$

Dimension of measurement volume, mm

Mass flow rate, $\mathrm{kg} / \mathrm{s}$

Mach number, -

Momentum flux rate, -

Ohnesorge number, -

Atomization gauge pressure, bar

Coefficient of determination, -

Reynolds number, -

Sauter mean diameter, $\mu \mathrm{m}$

Calculated SMD, $\mu \mathrm{m}$

Preheated liquid temperature, ${ }^{\circ} \mathrm{C}$

Reference temperature, ${ }^{\circ} \mathrm{C}$

Velocity, m/s

Weber number, -

Axial distance, $\mathrm{mm}$

Dynamic viscosity, $\mathrm{kg} /(\mathrm{m} \cdot \mathrm{s})$

Density, $\mathrm{kg} / \mathrm{m}^{3}$

Surface tension, $\mathrm{N} / \mathrm{m}$

Kinematic viscosity, $\mathrm{mm}^{2} / \mathrm{s}$

Limiting viscosity of the liquid, $\mathrm{mm}^{2} / \mathrm{s}$

Diesel

Genetic algorithm

Light heating oil

Phase Doppler Anemometry

Rapeseed oil

Scatter Search

Water

Air

Liquid

Relative

projection in the $X Y Z$ coordinate system 


\section{Introduction}

Plain-jet airblast atomization, investigated in the present paper, is an excellent model platform to better understand the atomization phenomena. Besides its theoretical relevance, it is widely used in numerous fields from healthcare [1] through heat transfer enhancement [2] to combustion [3]. Our motivation comes from the last example since there is a technological push to replace fossil fuels with renewable ones to achieve a sustainable economy [4]. None of the renewable-based fuels has turned to be dominant in the past decades [5]; nevertheless, utilizing the locally available ones is usually a reasonable choice. Hence, liquid fuel combustion investigations with both long-chained hydrocarbons, like crude rapeseed oil [6] and light fuels, like aqueous ethanol [7], were performed earlier. The cited papers use an atomizer similar to the currently investigated one. During the evaluation of crop-originated fuels, their impact on food security should firstly be taken into account [8]. Comparing various renewable fuels and technologies is crucial for decision making to select the best candidate and utilize it most efficiently. For this purpose, the ethanol equivalent is a reasonable basis since the production, and hence the energy balance of ethanol is well-known [9].

Atomization was intensively investigated around the 1980s [10], principally investigating water, kerosene, diesel oil, and various oil sprays at ambient temperature [11]. At that time, the effects of atomizing air temperature and operating pressure were in focus due to the market pull by the gas turbine industry [12]. Due to the available measurement technology at that time, the semi-empirical estimations of the average droplet size were limited to $100 \mathrm{~m} / \mathrm{s}$ air discharge velocity in the case of airblast atomizers [13]. In combustion applications, the droplets have to evaporate prior to the flame front. Hence, the volume-to-surface diameter $\left(D_{32}\right)$ or Sauter Mean Diameter $(S M D)$ is determined instead of other average diameter types. This is defined as follows: 


$$
S M D=\sum_{i} D_{i}^{3} / \sum_{i} D_{i}^{2},
$$

where $D_{i}$ is the diameter of a single droplet at a single measurement point. It was discussed in our previous work [14] that the suggested formula of Lefebvre [10], detailed at first in Section 2, estimated the $S M D$ most accurately. Nevertheless, the investigated air discharge velocity range was $200-500 \mathrm{~m} / \mathrm{s}$ in our case, which far exceeds the original validity range of $10-120 \mathrm{~m} / \mathrm{s}$.

Injection of light fuels at ambient temperature is usually adequate for efficient combustion. However, various long-chained oils - which have an emerging relevance as renewable fuels - need preheating [15]. Wang and Lefebvre [16] discussed the effect of fuel preheating, emphasizing that it reduces the $S M D$ and its effect seems independent of the ambient pressure. The researchers published plain measurement results and performed no statistical evaluation or comparison with the estimated SMD. More recently, Shah and Ganesh [17] measured the relevant temperature-dependent properties of karanj oil, which is a straight vegetable oil type. The researchers directly put the measurement data into an SMD-estimating equation, but the experimental validation of the results was not discussed. Hanna and Zoughaib [18] experienced a temperature change of the atomized compressor lubricant oil. However, they did not control the injection temperature systematically, and the measurements were limited to the range of $11-27^{\circ} \mathrm{C}$. Fuel preheating in internal combustion engine was performed by Park et al. [19], leading to a similar result as that of Wang and Lefebvre. The present paper focuses on the atmospheric temperature-dependent spray characteristics of the following model liquids to cover a relatively wide range of viscosity, which is one of the novelties of the present paper. Atomization of distilled water (W), standard diesel oil (D, EN 590:2014), light heating oil (LHO), and crude rapeseed oil (RO) were investigated in the liquid preheating temperature range of 25- 
$100{ }^{\circ} \mathrm{C}$ which partially covers, e.g., the thermal stability range of the pyrolysis oils as well [2022]. These temperature limits for the four liquids allows the investigation of a wide physical parameter range. I.e., for liquid viscosity, it covers more than two magnitudes. The corresponding measured liquid properties are summarized in Appendix A. A key issue in many of the empirical correlations published to date is that they are generally only tested on simple fuels over a very narrow range of physical properties, therefore making correlations to date of limited use. Hence, the resulting wide non-dimensional space allows the re-assessment of the existing empirical correlations, which is the principal goal of the present paper.

The scientific relevance of atmospheric measurements is often questioned by researchers since the operating pressure of e.g. gas turbines is several tens of bars [23]. It was shown by Zheng et al. [24] that $S M D$ varies slightly up to 12 bar in a gas turbine combustion chamber. Chigier [3] highlighted that the engine startup - when atomization occurs at reduced pressure is the most critical phase. Then, operation characteristics, including flammability limits and fuelair mixture quality at the flame front, start to improve.

Nukiyama and Tanasawa [25], the first systematic investigators of airblast atomization, pointed out that the mean droplet diameter depends on surface tension, density, fluid viscosity, volume flow rates of air and liquid, and the relative velocity between the two phases. The governing dimensionless numbers of airblast atomization are Reynolds number $(R e)$, Weber number (We), Ohnesorge number $(\mathrm{Oh})$, and air-to-liquid mass flow ratio $(A L R)$, defined by Eqs. (2)-(5):

$$
\begin{gathered}
\operatorname{Re}=u_{r} \cdot d \cdot \rho / \mu, \\
W e=u_{r}^{2} \cdot d \cdot \rho / \sigma, \\
O h=W e^{0.5} / \operatorname{Re}=\mu /(\sigma \cdot d \cdot \rho)^{0.5},
\end{gathered}
$$




$$
A L R=m_{a} / m_{l}
$$

where $u_{r}$ is the relative velocity between the air and the liquid, $d$ is a characteristic size, $\rho$ is the density, $\mu$ is the dynamic viscosity, $\sigma$ is the surface tension, and $m$ is the mass flow rate. $a$ and $l$ subscripts refer to air and liquid, respectively. Later on, if $R e$ or We receive an $A$ or $L$ subscript, the equations refer to the fluid used for the density and dynamic viscosity calculation.

Non-intrusive spray measurements can be performed by both imaging and non-imaging optical techniques [11]. For size characterization, the Phase Doppler technique is used most widely. In parallel, high-speed imaging is usually applied for qualitative analysis [26,27]. The present study is primarily focused on the results of Phase Doppler Anemometry (PDA) measurements.

Full simulation of atomization in a practical combustion chamber is unfeasible at the present time since the control volume of one liter would require $\sim 10^{20}$ cells. Such a detailed mesh is necessary for tracking liquid fractions down to one $\mu \mathrm{m}$ by the Eulerian approach. However, there are spectacular results achieved recently by the PAMELA software code [28] for prefilming airblast atomizers; its application in engineering practice requires the additional refinement and development to be extended for other atomizer types. Nevertheless, the primary liquid breakup in three dimensions can be modeled with the present computational capabilities [29-31]. Atomization simulation in a mixed Eulerian-Lagrangian space is common in computational fluid dynamics software codes [32]. This approach is characterized by several magnitudes lower computational time as the mesh size can be significantly smaller. However, the corresponding models strongly rely on empirical formulae [32]. Hence, improving these models through analyzing the results of systematic measurements has a notable importance even today. Consequently, the present paper provides the analysis of measurement data in a wide parameter 
range to enhance these atomizer models and provide a more realistic performance in engineering applications. I.e., the present results facilitate the atomization modeling of e.g. typical liquid fuels from crude vegetable oil to light fuels.

Concluding from the above findings, the effect of liquid preheating on atomization characteristics has both theoretical and practical relevance. Therefore, the principal aim of this work is to analyze quantitatively the global and local spray characteristics of various liquids atomized by an atmospheric plain-jet airblast atomizer. The high air discharge velocities with the preheating temperature range of $25-100{ }^{\circ} \mathrm{C}$ for four liquids (W, D, LHO, and RO) incorporate a wide non-dimensional parameter range, summarized in a tabular form in the end of Section 3. Therefore, re-assessment of the existing $S M D$-estimating formulae - reviewed in Section 2 - is discussed with the inclusion of the effect of liquid preheating.

\section{Review of SMD-estimating formulae of airblast atomization}

This section reviews six different empirical and semi-empirical formulae for estimating $S M D$, which were derived from optical measurements. Each contains at least one empirical parameter to be determined by a fitting method, which is lastly discussed.

\subsection{SMD-estimating formulae}

Previous empirical regression analyses lead to the conclusion that $S M D$ is primarily governed by We, $O h$, and $A L R$, for plain-jet airblast atomizers which were discussed by several

researchers [11,13,23]. Equation (6) shows the most widely used equation for airblast atomization, principally derived for the prefilming type [10]:

$$
S M D=d_{0}(1+1 / A L R)\left(A \cdot W e_{a}^{C}+B \cdot O h_{l}^{E}\right),(6 \text { Chyba! Záložka není }
$$




\section{definována.)}

where $A, B, C$, and $E$ are empirical parameters, and $d_{0}$ is a characteristic dimension which is the diameter of the liquid orifice in plain-jet airblast atomization. In line with preceding measurements, Lefebvre suggested $C=-0.5$ and $E=1$. Reducing the parameters from four to two also helps in avoiding equation overfitting. However, the present paper analyzes four variations of Eq. (6) in terms of $C$ and $E$ parameter values, summarized in Table 1.

Table 1. Investigated variations of Eq. 6.

\begin{tabular}{ccc}
\hline $\begin{array}{c}\text { modified } \\
\text { Eq. No. }\end{array}$ & value of $C$ & value of $E$ \\
\hline (6a) & $(-\infty, \infty)$ & $(-\infty, \infty)$ \\
$(6 \mathrm{~b})$ & {$[-5,+5]$} & {$[-5,+5]$} \\
(6c) & -0.5 & 0.5 \\
(6d) & -0.5 & 1 \\
\hline
\end{tabular}

Equation 6a represents a four-parameter variation without restriction. Equation (6b) is limited to $[-5,5]$ which helps in the convergence, and the fitted values were mostly in this regime. In the case of Eq. (6c) and Eq. (6d), the exponents are fixed at $C=-0.5, E=0.5$ and $C=-0.5, E=1$, respectively, resulting in two free parameters. The reason for two fixed exponents of $\mathrm{Oh}$ is that the value of $E$ was mostly between 0.5 and 1 during the fitting of Eqs. (6a) and (6b). Note that the measurement data used to derive Eq. (6) in ref. [33] is not discussed in scientifically adequate detail. Therefore, the range of validity of the upcoming equations is summarized only in Table 2, later in this section.

Based on Eq. (6), Eq. (7) is derived by Rizk and Lefebvre [34] which is the most widely applied empirical correlation for the estimation of $S M D$ in the case of airblast atomization: 


$$
S M D=d_{0}\left[F \cdot W e_{a}^{-0.4}(1+1 / A L R)^{0.4}+G \cdot O h_{l}(1+1 / A L R)\right]
$$

(7Chyba!

\section{Záložka není definována.)}

where $F=0.48$ and $G=0.15$ are frequently used parameter values [35-40].

A more recent formula for $S M D$ estimation of airblast atomization by a high-velocity gas stream was published by Varga et al. [13]. They attempted to overcome the empirical formulae, so they focused primarily on the disintegration of the liquid jet rather than the droplet sizes. In this context, the viscosity of the fluid is replaced by the viscosity of atomizing air. Although their efforts contributed greatly to the understanding of the atomization process, an empirical parameter, $H$, is still included in Eq. (8):

$$
S M D=\frac{0.68 H^{0.5}\left(\rho_{l} v_{a}\right)^{0.25} \sigma^{0.5}}{\rho_{a}^{0.75}\left[u_{a}\left(1+\sqrt{\rho_{a} / \rho_{l}}\right)-u_{l}\right] u_{a}^{0.25}},(8 C h y b a ! \quad \text { Záložka není }
$$

\section{definována.)}

where $v$ is the kinematic viscosity, and $H=0.055 \mathrm{~m}^{0.5}$ was determined based on their measurements. Comparing Eqs. (7) and (8), the most significant difference in terms of physical parameters is that Eq. (8) contains $v_{a}$ instead of $v_{l}$, and the characteristic size is absent. The exponent of the surface tension is 0.5, similar to that of Eqs. (6c) and (6d) through the We.

Eq. (9) was derived by Lorenzetto and Lefebvre [41] for water and kerosene. In this case, Oh appears similarly to the above equations except for Eq. (8). Due to the strong dependence of Eq. (9) on the geometry, Lefebvre preferred Eq. (7) over this one in his later publications. Recently, it was used by Chong and Hochgreb [37]. 


$$
S M D=\left[I \cdot\left[\frac{\left(\sigma \cdot \mu_{l}\right)^{0.33}}{\rho_{l}^{0,37} \cdot \rho_{a}{ }^{0.3} \cdot u_{r}}\right]+J \cdot\left[\frac{\mu_{l}^{2} \cdot d_{0}}{\sigma \cdot \rho_{l}}\right]^{0.5}\right] \cdot(1+1 / A L R)^{1.70},
$$

where $I$ and $J$ are empirical parameters. Note that the dimension of $I$ is $\mathrm{m}^{0.33}$. Equation (10) was derived by Jasuja [42,43] for residual fuel oils:

$$
S M D=K \cdot\left(\frac{\sigma}{u_{a}^{2} \cdot \rho_{a}}\right)^{0.45} \cdot(1+1 / A L R)^{0.5}+L \cdot\left(\frac{\mu_{l}^{2}}{\sigma \cdot \rho_{l}}\right)^{0.4} \cdot(1+1 / A L R)^{0.8},
$$

where $K$ and $L$ parameter values were 0.19 and 0.127 . According to dimensional analysis, the units of $K$ and $L$ are $\mathrm{m}^{0.55}$ and $\mathrm{m}^{0.6}$, repsectively. The structure of this equation is quite similar to Eqs. (6a) and (7) in terms of $W e, O h$, and $A L R$, only the exponents were modified, and the characteristic size is also missing. Equation (11) was published by the present authors in the preceding paper [14] investigating diesel oil atomization:

$$
S M D=M \cdot d_{0} \cdot(1+1 / A L R)\left(A \cdot W e_{a}^{-0.5}\right),
$$

where $M$ is an experimental parameter. The conclusion, which leads to Eq. (11), was that $O h$ plays a negligible role in the case of high-velocity atomization. Moreover, $M$ was in good agreement with the typical values of Eq. (7) regardless of different atomizer design, i.e., plainjet vs. prefilming-type. Table 2 summarizes the range of investigation of the above-detailed equations except for Eq. 6 since it was not discussed in ref. [33].

Table 2. The validity of the examined equations published by the listed authors. Note that $A L R$ in Eq. (8) was not discussed in [13]; it is an estimation based on the atomizer geometry and the measurement results.

\begin{tabular}{ccccccccc}
\hline Researchers & Eq. & Liquids employed & $\begin{array}{c}\sigma \times 10^{-3} \\
{[\mathrm{~N} / \mathrm{m}]}\end{array}$ & $\begin{array}{c}\rho_{L} \\
{\left[\mathrm{~kg} / \mathrm{m}^{3}\right]}\end{array}$ & $\begin{array}{c}\mu_{L} \times 10^{6} \\
{[\mathrm{~kg} / \mathrm{m} \cdot \mathrm{s}]}\end{array}$ & $\begin{array}{c}u_{A} \\
{[\mathrm{~m} / \mathrm{s}]}\end{array}$ & $\begin{array}{c}A L R \\
{[-]}\end{array}$ & $\begin{array}{c}S M D \\
{[\mu \mathrm{m}]}\end{array}$ \\
\hline $\begin{array}{c}\text { Rizk and } \\
\text { Lefebvre [34] } \\
\begin{array}{c}\text { Varga et al. } \\
\text { [13] }\end{array}\end{array}$ & (7) & $\begin{array}{c}\text { Kerosene, gas oil, } \\
\text { blended oils }\end{array}$ & $27-29$ & $780-840$ & $1.3-3$ & $10-120$ & $2-8$ & $15-110$ \\
& Water, ethanol & $23-70$ & $791-998$ & $1-1.2$ & $30-165$ & $3.9-25.6$ & $18-170$
\end{tabular}




\begin{tabular}{ccccccccc}
$\begin{array}{c}\text { Lorenzetto and } \\
\text { Lefebvre [41] }\end{array}$ & $(9)$ & $\begin{array}{c}\text { Water, kerosene, } \\
\text { special solutions }\end{array}$ & $26-76$ & $794-2180$ & $1-76$ & $60-180$ & $1-16$ & $20-130$ \\
$\begin{array}{c}\text { Jasuja [42,43] } \\
\text { Urbán et al. }\end{array}$ & $(10)$ & residual fuel oils & $21-74$ & $784-1000$ & $1-53$ & $70-135$ & $2-18$ & $35-120$ \\
[14] & $(11)$ & diesel oil & 28 & 830.3 & 3.45 & $207-445$ & $0.78-2.3$ & $5-100$ \\
\hline
\end{tabular}

Interestingly, only a few papers discuss the airblast atomization under supersonic conditions, see, e.g., refs. [37,44-46]. Kihm and Chigier concluded that air discharge velocities above supersonic reduce the SMD only due to the increased relative velocity. Even though there are shock waves present, they negligibly affect the droplet size. Therefore, the supersonic and subsonic regimes can be presented and discussed on the same plot without concerns.

\subsection{Parameter fitting to experimental data}

To fit with the present experimental data, the parameters of each SMD-estimating equation were determined using the least squares method:

$$
\sum_{i}\left[S M D_{\text {calc }}\left(P_{i}\right)-I S M D_{\text {meas }}\right]^{2}=\min .
$$

where $P_{i}$ represents all the parameters in Eqs. (6) - (11), and ISMD is the integral SMD of the spray. Since $S M D$ is a local parameter of a single point measurement by PDA, it has to be integrated over the control area to end up with a single $S M D$ value which characterizes the spray, ISMD. Its calculation is discussed by Jedelsky and Jicha [47]. The subscripts calc and meas refer to the calculated and measured values, respectively.

The parameter fitting was implemented in MATLAB software environment where the parameters of each equation were defined as symbolic variables. To ensure the best fit, a Globalsearch solver engine was applied; it uses a Scatter Search $(\mathrm{ScS})$ mechanism to generate the starting points. ScS is a population-based metaheuristic algorithm devised to perform a search 
for the problem domain intelligently. Hence, besides Eq. (6a), Eq. (6b) was added to have a finite search space for parameters $C$ and $E$. The solver analyzes a set of starting points and rejects the ones that are unlikely to improve the best local minimum found so far. The population elements are then updated. ScS differs from other population-based evolutionary heuristics, like genetic algorithms (GA), mainly in the way of generating new candidates of the population. It uses deterministic combinations of previous members of the population as opposed to a more extensively used randomization in GAs. It embodies principles and strategies that are still not emulated by other methods and prove to be advantageous for solving a variety of complex optimization problems [48].

\section{Experimental setup}

This section starts with a discussion over the investigated atomizer, then the PDA setup is detailed. It is followed by the introduction of the test rig which provided the well-controlled inlet conditions. Finally, the measurement schedule and the measurement parameter ranges are discussed.

The cross-section of the atomizer is shown in Fig. 1. The liquid flows through a pipe with a $0.4 \mathrm{~mm}$ inner diameter while the atomizing air discharges from a concentric annulus $(1.6 \mathrm{~mm}$ outer, $0.8 \mathrm{~mm}$ inner diameter) and interacts with the liquid stream. The high-velocity air blows over the surface of the low-velocity liquid jet which leads to a rapid disintegration of the liquid jet into ligaments and then into tiny droplets. In the present case, the diameter of the liquid jet was used as a characteristic size, i.e. $d_{0}=0.4 \mathrm{~mm}$. This particular atomizer was examined by several researchers $[14,40,49-52]$ due to its simple geometry and operation. 


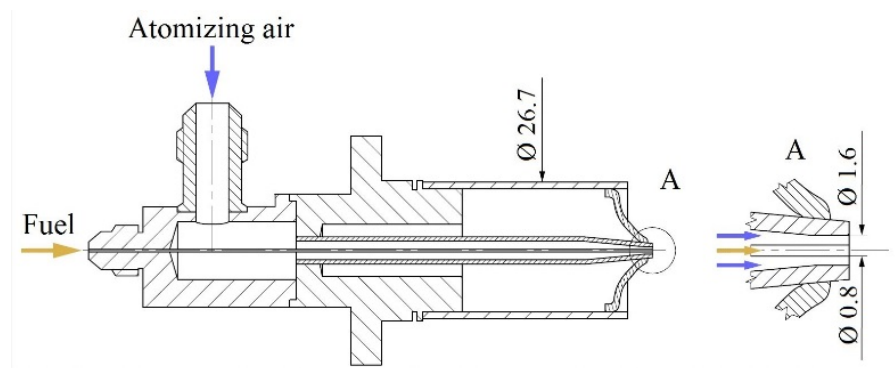

Fig. 1. Cross-section of the investigated atomizer.

The typical droplet sizes are in the micrometer range; hence, a two-component Fiberbased PDA, made by Dantec Dynamics A/S (Skovlunde, DK), was used for droplet size and velocity measurements. Its schematic setup is shown in Fig 2 with measurement points along $X$ and $Y$ directions. Here, the optical system was fixed while a computer-controlled 3D traverse system positioned the atomizer.

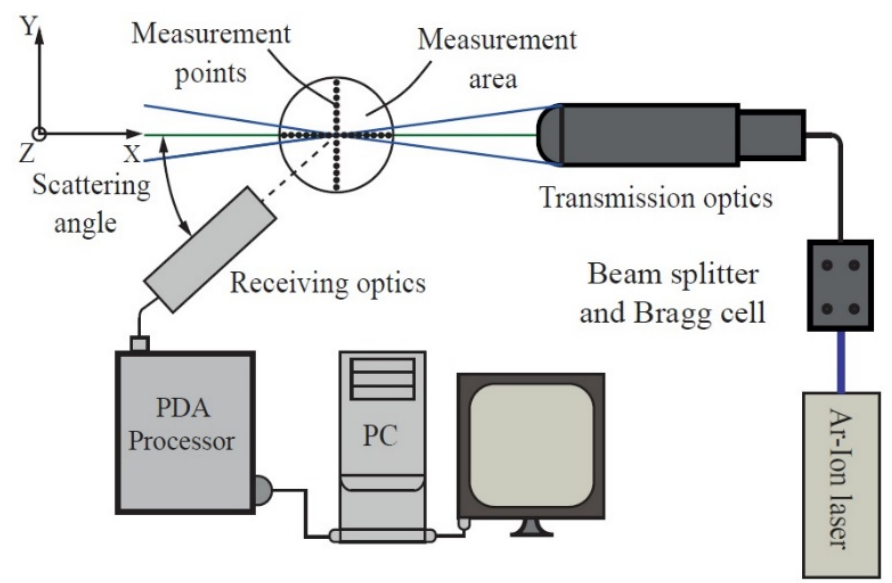

Fig. 2. Setup of the PDA system.

A Spectra-Physics (CA, USA) Stabilite 2017 argon-ion laser produced a multi-line laser beam which was split by a 60X41 transmitter into its color components. Green and blue colors with wavelengths of 514.5 and $488 \mathrm{~mm}$, respectively, were used and divided into two equivalent, horizontally polarized beams. A Brag cell, implemented in the transmitter, provided a frequency shift of $40 \mathrm{MHz}$ to one beam from each pair. Transmitting optics 60X81 2D $85 \mathrm{~mm}$ with 50X82 beam translator provided the two pairs of the green and blue laser beams which were used for the axial and radial velocity measurements, respectively. A 57X50 fiber PDA receiver optics was 
used with a lens of $112 \mathrm{~mm}$ diameter. The focal length was 310 and $500 \mathrm{~mm}$ for the transmitting and the receiving optics, respectively. The half-intersection angle between the laser beams was set to $6.92^{\circ}$. Dimensions of the measurement volume were $l_{x}=0.60 \mathrm{~mm}, l_{y}=0.072 \mathrm{~mm}, l_{z}=$ $0.073 \mathrm{~mm}$, according to the coordinate system in Fig. 2. A spatial filter with a slit size of $0.1 \mathrm{~mm}$ was used to reduce the $l_{x}$ dimension of the measurement volume. The scattering angle was set to Brewster's angle, $68^{\circ}[53]$.

The measured signals were processed by the BSA P80 flow and the particle processor and visualized by BSA Flow Software v5.2. The modular instrument was configured for the measurement in the dense spray containing small droplets. The droplet velocities notably varied in space and were sensitive to the inlet conditions. Hence, the system parameters were set individually for different inlet pressures and axial distances from the atomizer nozzle.

The maximum droplet size to measure was set to $64.1 \mu \mathrm{m}$ with a size resolution of \pm 0.05 $\mu \mathrm{m}$ and uncertainty of $\pm 0.5 \mu \mathrm{m}$. The particle refractive index was set to 1.45 for all oils and 1.33 for water. The axial and radial velocity range was set from $0-64 \mathrm{~m} / \mathrm{s}$ to $0-144 \mathrm{~m} / \mathrm{s}$ and $0-46 \mathrm{~m} / \mathrm{s}$ to $0-98 \mathrm{~m} / \mathrm{s}$, respectively, considering the effects of axial distance from the atomizer nozzle and the atomizing pressure on the maximum droplet velocity. For this reason, the velocity span was set from $128 \mathrm{~m} / \mathrm{s}$ to $192 \mathrm{~m} / \mathrm{s}$. The velocity resolution was $0.002 \%$, and the uncertainty was less than $1 \%$ of the selected range. The PDA system was set to acquire 40,000 individual particles or measure for 15 seconds in the low-density regions. According to the preliminary results (not shown here), the spray was found to be axisymmetric.

The experimental atmospheric test rig is shown in Fig. 3. The atomizing air was taken from the central compressed air system through a pressure regulator followed by a mass flow meter towards the atomizer. The following atomizing gauge pressures, $p_{g}$, were investigated: 0.3 , $0.6,0.9,1.2,1.8$, and 2.4 bar. The lowest value was selected based on the criteria of stable 
combustion in the hot test cases - without spray measurement - [50,54]. A pressurized tank was used to feed the liquids into the atomizer without fluctuation. A control valve and a Coriolis mass flow meter Mass 2100 Di3 fitted with the Mass 6000 transmitter (Siemens AG, GE) were applied to set a constant $0.35 \mathrm{~g} / \mathrm{s}$ liquid mass flow rate with an accuracy of $\pm 0.1 \%$ of the actual flow rate. A rotameter was also installed into the feed pipe for visual checking. Both liquid and atomizing air lines were equipped with piezo-resistive pressure transducers DMP 331i (BD SENSORS s.r.o., CZ) and B class Pt100 resistance thermometers. The uncertainty was $2 \mathrm{kPa}$ and $0.3^{\circ} \mathrm{C}$ in the pressure and temperature sensing, respectively. The resulting $A L R$ range of all measurements was $0.78-2.07$.

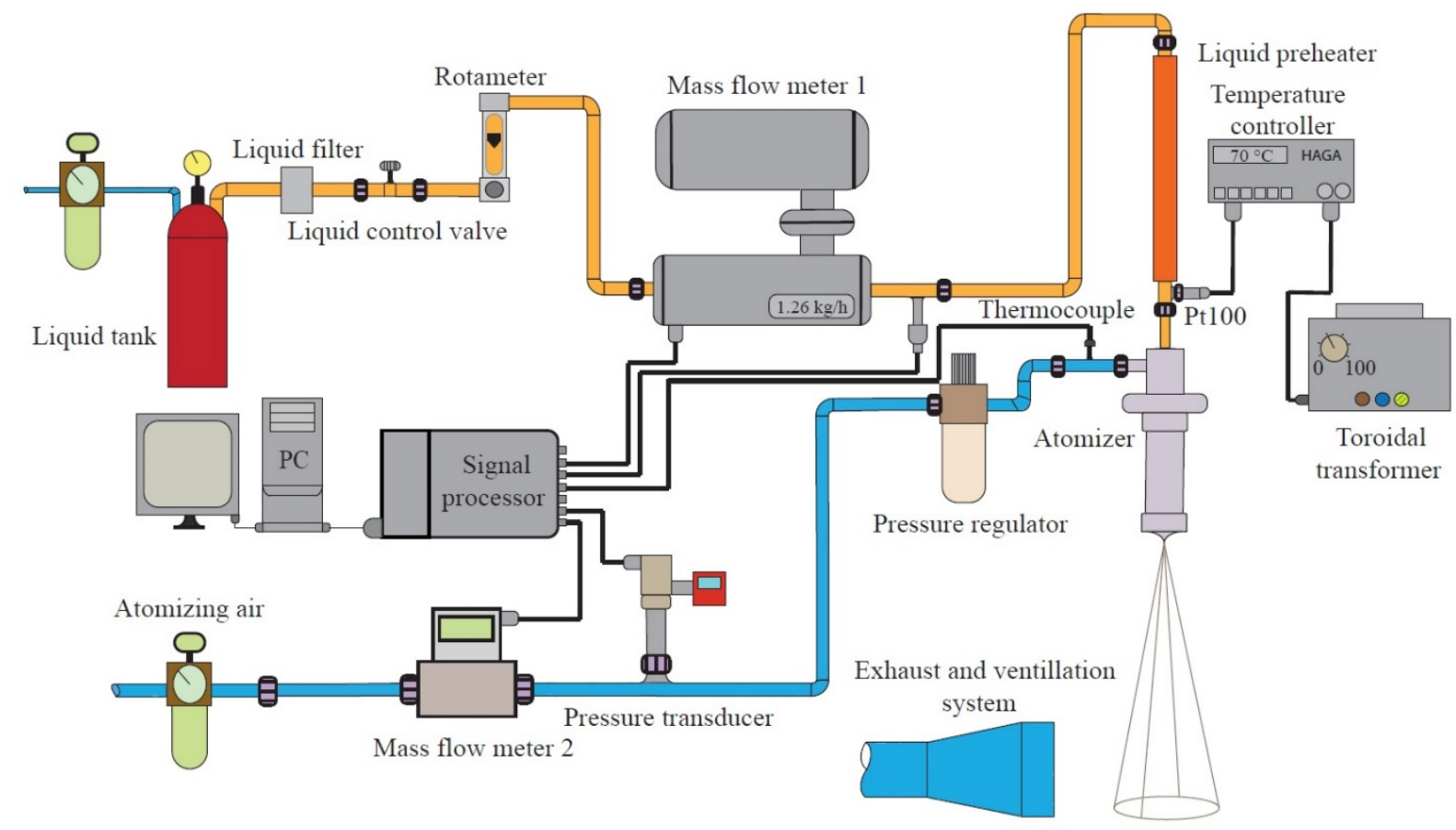

Fig. 3. Liquid and atomizing air supply lines and their instrumentation of the experimental test rig.

The liquid preheater was controlled by a PID unit made by HAGA Kft. using a temperature control signal of a Pt100 resistance temperature detector. A toroidal transformer was used to set the heating power of the PID control to avoid outlet temperature oscillations. The following preheating temperatures, $t_{p}$, were investigated for D, LHO, and RO: 25, 40, 55, 70 and 
$100{ }^{\circ} \mathrm{C} . \mathrm{W}$ is an exception from this series since the maximum temperature was $90{ }^{\circ} \mathrm{C}$ to avoid boiling, but the lower $t_{p}$ s were the same. The relevant physical properties of the liquids and their measurement methods were presented in Appendix A.

The PDA measurements were carried out at three axial distances downstream of the nozzle, $z=20$, 40 and $60 \mathrm{~mm}$, with fifteen equally spaced radial points along $X$ and $Y$ axes at $z=$ $60 \mathrm{~mm}$, thirteen at $z=40 \mathrm{~mm}$ and seventeen at $z=20 \mathrm{~mm}$. At $z=20 \mathrm{~mm}$, the step was $1 \mathrm{~mm}$ between the points and $2 \mathrm{~mm}$ at $z=40$ and $60 \mathrm{~mm}$. Based on the analysis of the previous measurement results, the $z<20 \mathrm{~mm}$ regime was later rejected [14] as droplet velocities close to the nozzle exceed the limitations of PDA ( $\sim 300 \mathrm{~m} / \mathrm{s})$. Based on the results of our previous studies, $z=60 \mathrm{~mm}$ was found to be a sufficient downstream distance to ensure a fully developed, stable spray that was suitable for ISMD calculation.

Besides the mentioned dimensionless numbers, defined by Eqs. (2) - (5), the momentum flux rate, $M F R$, energy flux rate, $E F R$, and Mach number, $M a$, are also key parameters of airblast atomization. They are defined by Eqs. (13) - (15):

$$
\begin{gathered}
M F R=\rho_{a} \cdot u_{a}^{2} /\left(\rho_{l} \cdot u_{l}^{2}\right), \\
E F R=\rho_{a} \cdot u_{a}^{3} /\left(\rho_{l} \cdot u_{l}^{3}\right), \\
M a=u_{a} / a,
\end{gathered}
$$

where $a$ is the speed of sound. All the mentioned dimensionless numbers, including $R e$ and $W e$ for both air and liquid phases are summarized in Table 3 to show the range of investigated cases. 
Table 3. Intervals of the investigation ranges of the liquids.

\begin{tabular}{|c|c|c|c|c|c|}
\hline & & $\mathrm{D}$ & LHO & $\mathrm{RO}$ & $\mathrm{W}$ \\
\hline \multirow{2}{*}{$p_{g}[\mathrm{bar}]$} & $\min$. & 0.3 & 0.3 & 0.3 & 0.3 \\
\hline & $\max$. & 2.4 & 2.4 & 2.4 & 2.4 \\
\hline \multirow{2}{*}{$A L R[-]$} & $\min$. & 0.78 & 0.78 & 0.78 & 0.78 \\
\hline & $\max$. & 2.07 & 2.07 & 2.07 & 2.07 \\
\hline \multirow{2}{*}{$R e_{a}[-]$} & $\min$. & 8969 & 8974 & 8979 & 8994 \\
\hline & $\max$. & 30037 & 30047 & 30058 & 30075 \\
\hline \multirow{2}{*}{$\operatorname{Re}_{l}[-]$} & $\min$. & 22749452 & 5035776 & 1565911 & 91217176 \\
\hline & $\max$. & 115408537 & 51798814 & 21023241 & 380150588 \\
\hline \multirow{2}{*}{$W e_{a}[-]$} & $\min$. & 988.4 & 792.5 & 730.6 & 289.7 \\
\hline & max. & 9549 & 4640 & 5014 & 1982 \\
\hline \multirow{2}{*}{$W e_{a}[-]$} & $\min$. & 655242 & 550332 & 531391 & 228328 \\
\hline & $\max$. & 4638184 & 2346382 & 2626442 & 1157407 \\
\hline \multirow{2}{*}{ Oh [-] } & $\min$. & 0.019 & 0.029 & 0.077 & 0.0028 \\
\hline & $\max$. & 0.036 & 0.147 & 0.465 & 0.0052 \\
\hline \multirow{2}{*}{$M a[-]$} & $\min$. & 0.62 & 0.62 & 0.62 & 0.62 \\
\hline & $\max$. & 1.45 & 1.45 & 1.45 & 1.45 \\
\hline \multirow{2}{*}{$M F R[-]$} & $\min$. & 5.68 & 5.91 & 6.13 & 6.83 \\
\hline & $\max$. & 31.7 & 33.23 & 34.8 & 37.7 \\
\hline \multirow{2}{*}{$E F R[-]$} & $\min$. & 342.2 & 370.9 & 398 & 494.7 \\
\hline & max. & 4011 & 4401 & 4828 & 5667 \\
\hline \multirow{2}{*}{$I S M D / d_{0}[-]$} & $\min$. & 0.0216 & 0.0218 & 0.0278 & 0.0244 \\
\hline & $\max$. & 0.0652 & 0.0656 & 0.0671 & 0.0691 \\
\hline
\end{tabular}

\section{Results and discussion}

Firstly, this section focuses on the droplet size-velocity correlation at various $p_{g}$ and $t_{p}$ to evaluate single measurement points for all four liquids. Secondly, the temperature-dependent characteristics of SMD estimating formulae are discussed and adjusted to fit the effects of preheating temperature. Hence, the governing parameters were identified and included in the experimentally determined constant parameters.

\subsection{Droplet size-velocity correlations}

The liquid jet is disrupted by the shear effect of the flowing gas, and the newly created liquid fractions are further accelerated, which leads to the formation of ligaments; these then break up into smaller droplets. The larger droplets, accelerated by the atomizing air near the nozzle, typically lose their momentum slower than the surrounding gas jet. Hence, it leads to a 
reverse momentum exchange between the gas and liquid phases downstream, which is called overshooting $[14,55]$.

Figures 4-7 show typical radial-axial velocity scatter plots at selected atomization gauge pressures and liquid temperatures for all four liquids at the center, and $z=60 \mathrm{~mm}$ of the fully developed spray. The results of the near field can be found in our previous work [14] and are not discussed here since the results were quite similar. Now the focus is on the effects of liquid preheating on the spray at only three $t_{p}$ and $p_{g}$. The rest of the cases followed the same trend. Note that the logarithm of the droplet diameter gives the base of coloring to help distinguishing various sizes and hence characteristics.

A droplet velocity has a dominant axial component while the radial component remains relatively low with decreasing atomizing pressure. The swirl component was below $10 \mathrm{~m} / \mathrm{s}$ even at high atomizing pressures. Since the used PDA measures two perpendicular velocity components simultaneously, the swirl velocity was omitted in the systematic analysis. As for the axial velocity distribution, the results follow a similar trend; in general, the larger droplets have a higher velocity. However, the radial components tend to increase evenly with the atomizing pressure of all droplets. At $t_{p}=100{ }^{\circ} \mathrm{C}$ and $p_{g}=1.8 \mathrm{bar}$, the majority of droplets in the spray are smaller than $20 \mu \mathrm{m}$, and the droplet size range is narrow. As the spray develops, the smaller droplets lose their momentum faster, clearly showing the phenomenon of overshooting. 

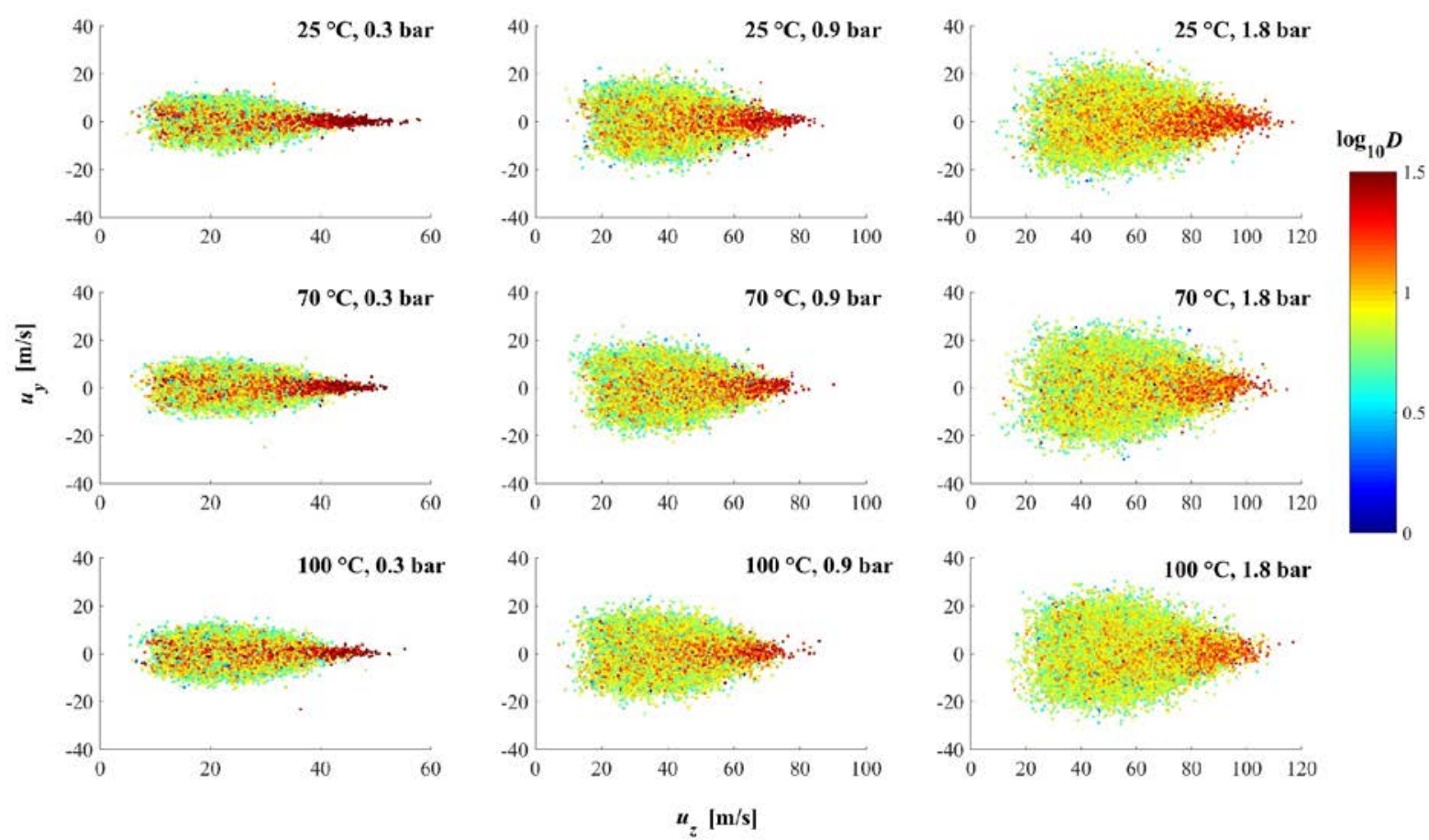

Fig. 4. Size-velocity correlation at $x=y=0 \mathrm{~mm}$ and $z=60 \mathrm{~mm}$ in the case of diesel oil (D) at various $t_{p}$ and $p_{g}$.
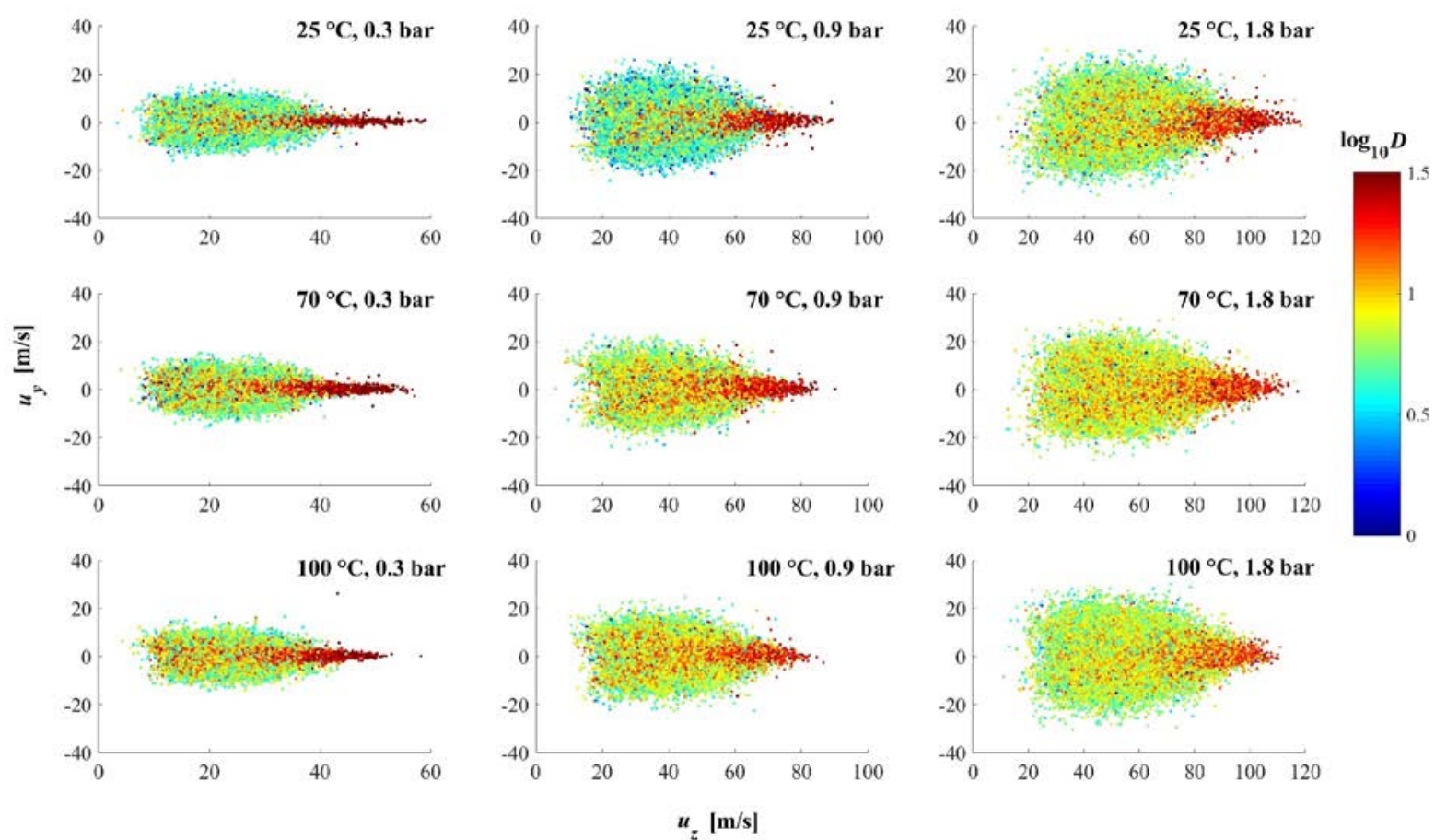

Fig. 5. Size-velocity correlation at $x=y=0 \mathrm{~mm}$ and $z=60 \mathrm{~mm}$ in the case of light heating oil (LHO) at various $t_{p}$ and $p_{g}$. 

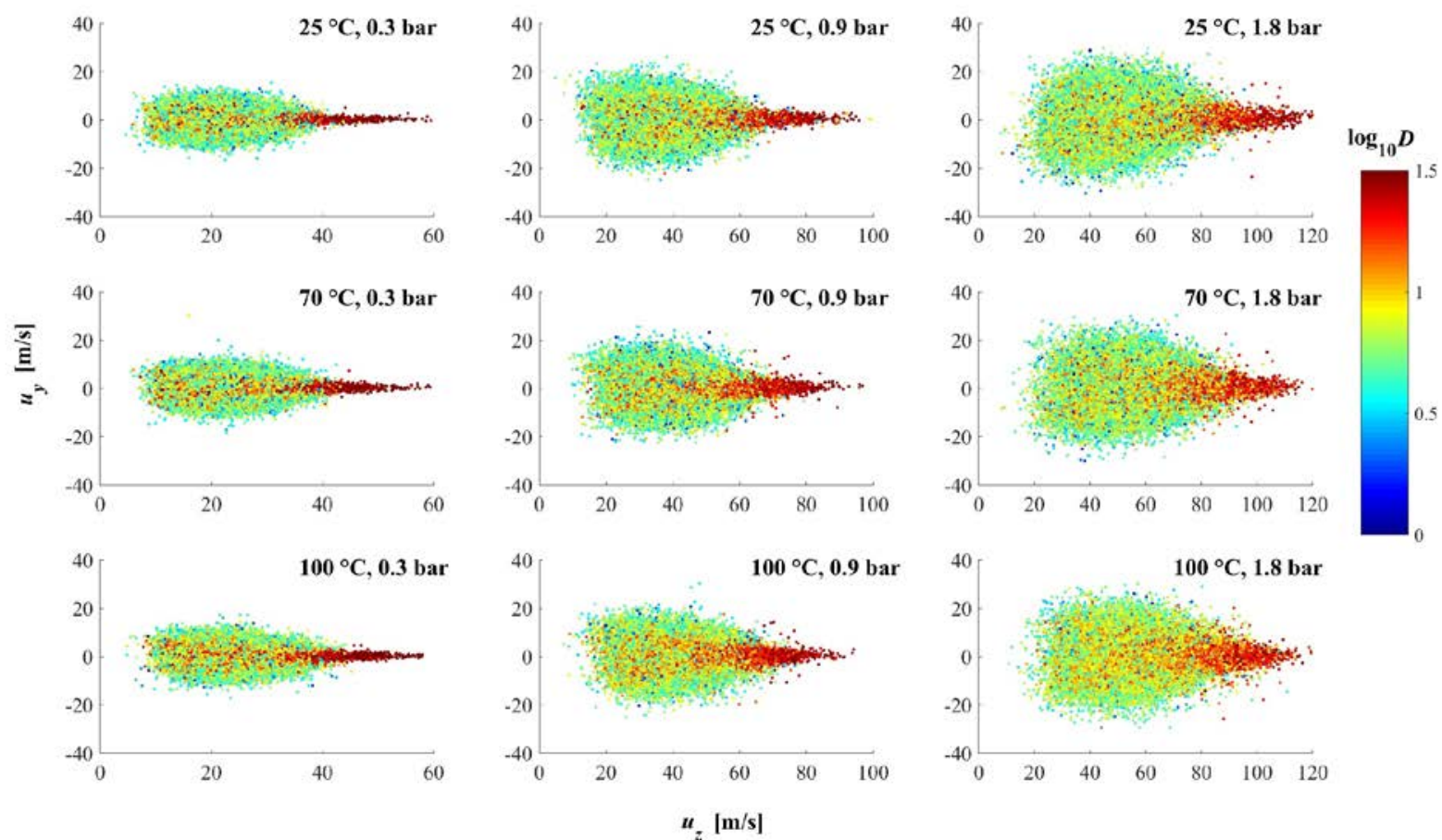

Fig. 6. Size-velocity correlation at $x=y=0 \mathrm{~mm}$ and $z=60 \mathrm{~mm}$ in the case of rapeseed oil (RO) at various $t_{p}$ and $p_{g}$.
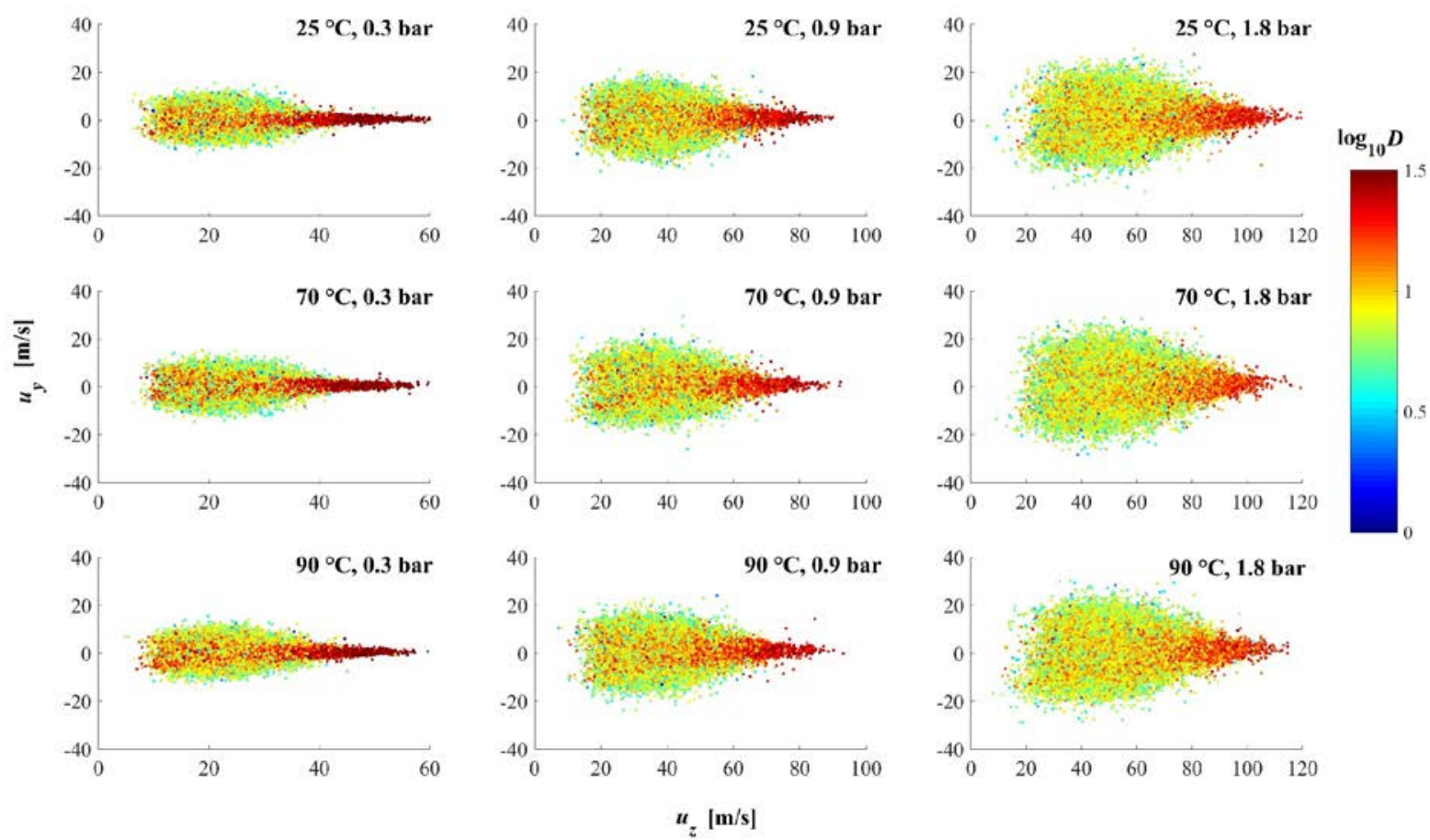

Fig. 7. Size-velocity correlation at $x=y=0 \mathrm{~mm}$ and $z=60 \mathrm{~mm}$ in the case of water (W) at various $t_{p}$ and $p_{g}$.

The droplet velocity variation, including both $u_{z}$ and $u_{y}$ components, is principally governed by $p_{g}$; liquid type and $t_{p}$ have a smaller effect on it. However, in the case of the high- 
viscosity LHO and RO, the plots significantly differ from D and W. This effect is further supported by the fact that only small droplets feature the same velocity scatter as it is in the D and $\mathrm{W}$ cases. The medium-sized droplets are concentrated on the horizontal axis while the large droplets are characterized by a similar scatter compared to D and W. The scatter of LHO at temperature of $100{ }^{\circ} \mathrm{C}$ becomes similar to that of the low viscosity liquids. Nevertheless, RO did not achieve this state since its viscosity at $100{ }^{\circ} \mathrm{C}$ is 2.4 times higher than that of $\mathrm{D}$ at $25^{\circ} \mathrm{C}$. Consequently, preheating of LHO up to $70{ }^{\circ} \mathrm{C}$ and above, discussed in subsection 4.2., leads to similar atomization characteristics as D. The poor atomization characteristics of RO were indirectly identified during the combustion tests [6]. The liquid from the same shipment - which was used for atomization measurements - was required to be preheated up to $150{ }^{\circ} \mathrm{C}$ to eliminate the presence of the burning droplets in the flame.

Overall, the increasing liquid temperature slightly reduces the SMDs, as shown in Fig. 8a. The increased atomizing pressure smoothens the droplet size distribution and makes it more monodisperse, as shown in Fig. 8b. It can be concluded from the two plots that atomizing pressure has a greater effect on the spray size distribution than the liquid preheating, as inertial forces govern the spray formation over viscous forces under the presently investigated conditions. Note that a rich statistical analysis of the present data on the size distribution in the spray will be published in a successor work. 
a)

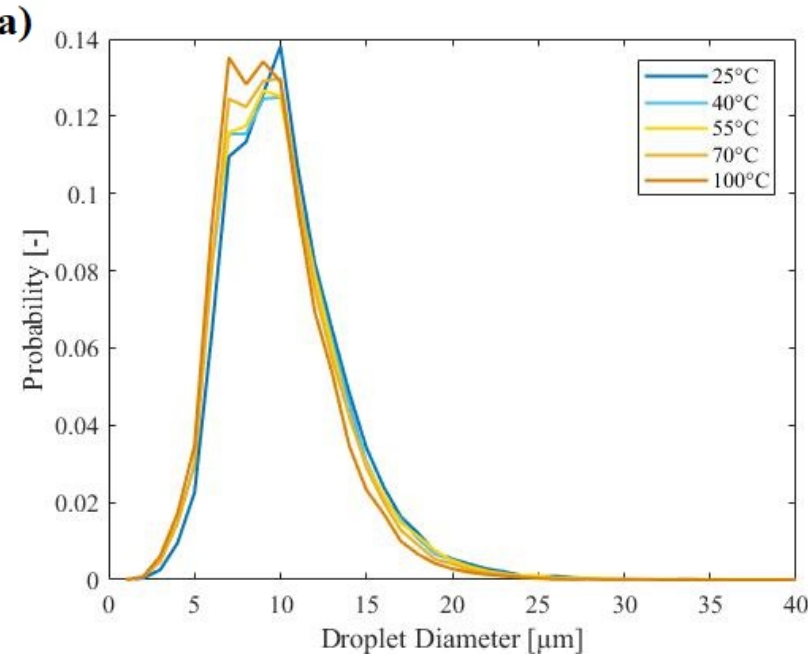

b)

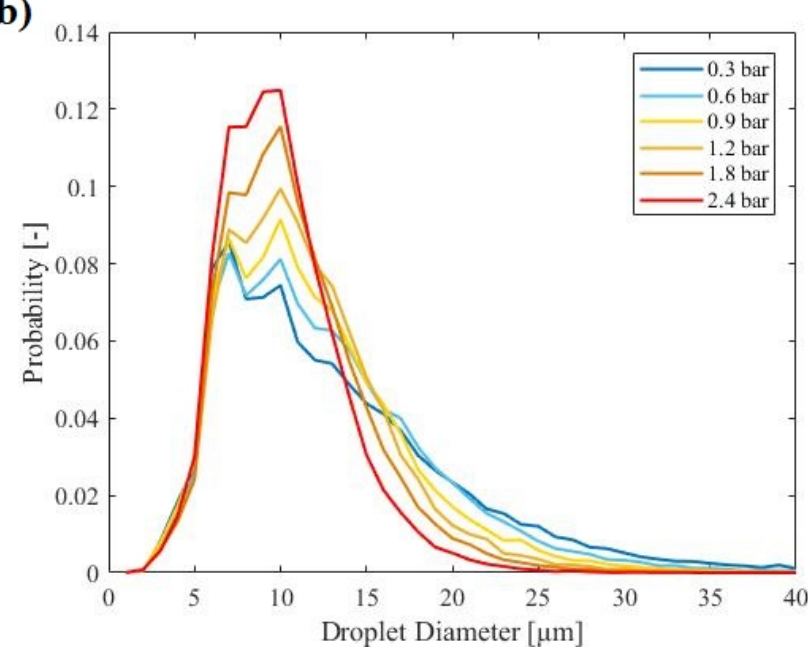

Fig. 8. Effect of a) $t_{p}$ and b) $p_{g}$ on droplet size distribution of $\mathrm{W}$ at $p_{g}=2.4$ bar and $t_{p}=25{ }^{\circ} \mathrm{C}$, respectively. The applied bin size was uniformly $1 \mu \mathrm{m}$.

\subsection{The temperature dependence of the SMD-estimating formulae}

Figure 9 shows ISMD of the measured data at $t_{p}=25^{\circ} \mathrm{C}$ and $z=60 \mathrm{~mm}$ for $\mathrm{D}$ and RO. While Fig. 9a suggests that all the formulae provide a reasonably good estimation for SMD, Fig. 9b shows that the effect of viscosity is poorly treated in Eqs. (8) and (11). These are the two extreme examples where the liquid viscosity was low (D) and high (RO) while the rest of the measurement parameters were matched. Nevertheless, this outcome was evident only in the latter case since $\mathrm{Oh}$ is absent in Eq. (11). Concluding from the results, it was a general observation that, when the liquid viscosity was below $\sim 4.3 \mathrm{~mm}^{2} / \mathrm{s}$, all the formulae provided a fair estimation 
of ISMD, even Eq. (11), where the term containing Oh is missing. This finding and the modern PDA system provide the answer why Kulkarni and Deshmukh [56] achieved the best estimation of $S M D$ in the case of airblast atomization of water by using Eq. (11).
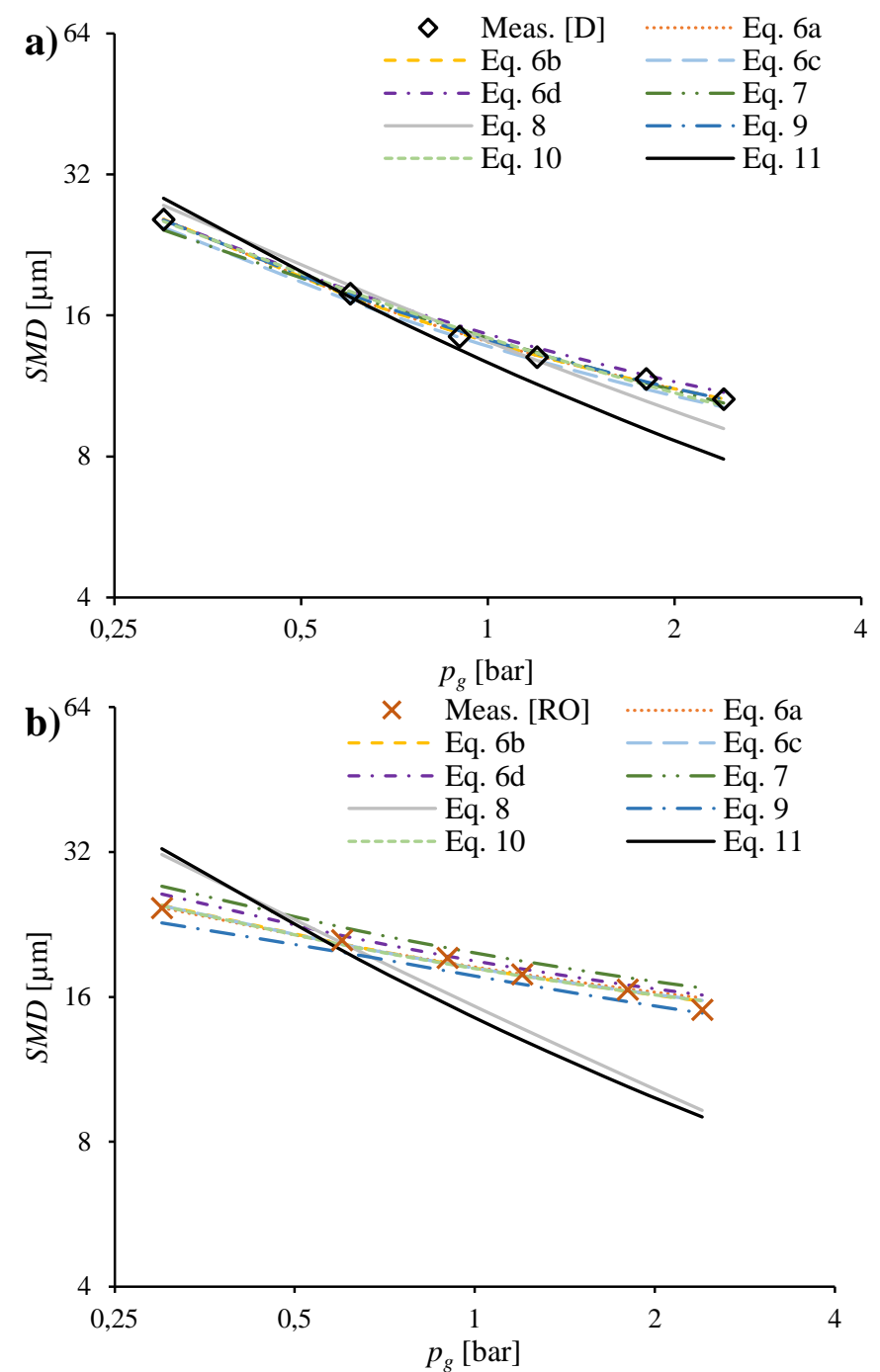

Fig. 9. Fitted $S M D$-estimating formulae at $t_{p}=25{ }^{\circ} \mathrm{C}$ and $z=60 \mathrm{~mm}$ in the case of a) D and b) RO. Note the log$\log$ scales.

To evaluate the fit quality quantitatively, $R^{2}$ values were summarized in Table 4. Equations (6a) - (7) represent a single type of $S M D$-estimating formulae. The exponents in Eq. (6a) were not limited. However, their typical values were in the $[-5,5]$ range. To achieve faster convergence and more accurate results, the exponents in Eq. (6b) were limited to this range. Note that the equations were fitted to the six measured pressure points for a given liquid and $t_{p}$. Hence, 
four parameters facilitate overfitting the equations. Since the exponent of $\mathrm{Oh}$ often fell between 0.5 and 1, both values were examined as Eqs. (6c) and (6d), respectively, see Table 1. There is no significant difference between them up to $55^{\circ} \mathrm{C}$, but the latter fits slightly better to the experimental data. Therefore, Eq. (6d) is the preferred variant of Eq. (6) in the upcoming analyses. Equation (7) fits well to the present data; nevertheless, it contains only modified exponents. Since Eqs. (8) and (11) were unable to estimate the $S M D$ with at least $R^{2}=0.75$ in several occasions, they were omitted in the subsequent parts. Even though Eqs. (9) and (10) are less popular in the atomization literature since the exponents were fitted to a limited data set without a deep theoretical analysis, their fit quality is excellent. As for $z=20$ and $40 \mathrm{~mm}$, the fitting method worked similarly as it was discussed above. The difference was of less accurate fit, i.e., $\sim 0.03$ lower $R^{2}$ values at $z=40 \mathrm{~mm}$ and $\sim 0.06$ decrease in $R^{2}$ at $z=20 \mathrm{~mm}$. However, the spray was not considered as fully developed at these downstream distances [14]. 
Table 4. $R^{2}$ of equation fitting for all the examined liquids at various $t_{p}$.

\begin{tabular}{|c|c|c|c|c|c|c|c|c|c|c|c|}
\hline$t_{p}\left[{ }^{\circ} \mathrm{C}\right]$ & Liq./Eq. & (6a) & (6b) & $(6 c)$ & $(6 d)$ & (7) & (8) & (9) & (10) & (11) & \\
\hline \multirow{4}{*}{25} & $\mathrm{D}$ & 1.00 & 1.00 & 0.99 & 0.98 & 0.99 & 0.95 & 1.00 & 1.00 & 0.83 & \\
\hline & LHO & 0.98 & 0.98 & 0.97 & 0.97 & 0.98 & - & 0.98 & 0.98 & - & \\
\hline & $\mathrm{RO}$ & 0.99 & 0.99 & 0.98 & 0.99 & 0.99 & - & 0.99 & 0.99 & - & \\
\hline & $\mathrm{W}$ & 0.98 & 0.97 & 0.96 & 0.96 & 0.97 & 0.82 & 0.96 & 0.97 & - & 1.00 \\
\hline \multirow{4}{*}{40} & $\mathrm{D}$ & 1.00 & 1.00 & 0.99 & 1.00 & 0.97 & 0.86 & 0.98 & 0.95 & 0.79 & 0.98 \\
\hline & LHO & 0.99 & 0.99 & 0.98 & 0.98 & 0.99 & - & 0.99 & 0.99 & - & 0.96 \\
\hline & $\mathrm{RO}$ & 0.95 & 0.97 & 0.95 & 0.95 & 0.96 & - & 0.97 & 0.95 & - & 0.94 \\
\hline & $\mathrm{W}$ & 0.98 & 0.98 & 0.97 & 0.95 & 0.98 & 0.82 & 0.97 & 0.98 & - & 0.92 \\
\hline \multirow{4}{*}{55} & $\mathrm{D}$ & 1.00 & 1.00 & 0.97 & 0.98 & 0.97 & 0.83 & 0.97 & 0.98 & 0.75 & 0.90 \\
\hline & LHO & 1.00 & 1.00 & 1.00 & 1.00 & 1.00 & - & 1.00 & 1.00 & - & 0.88 \\
\hline & RO & 0.97 & 0.97 & 0.96 & 0.96 & 0.97 & - & 0.98 & 0.97 & - & 0.86 \\
\hline & W & 0.98 & 0.97 & 0.96 & 0.95 & 0.98 & 0.86 & 0.96 & 0.97 & 0.76 & 0.84 \\
\hline \multirow{4}{*}{70} & $\mathrm{D}$ & 1.00 & 1.00 & 0.95 & 0.99 & 0.96 & 0.90 & 1.00 & 0.96 & 0.84 & 0.82 \\
\hline & LHO & 1.00 & 1.00 & 0.92 & 1.00 & 0.98 & 0.81 & 1.00 & 0.96 & - & 0.80 \\
\hline & $\mathrm{RO}$ & 0.98 & 0.97 & 0.95 & 0.96 & 0.97 & - & 0.97 & 0.97 & - & 0.78 \\
\hline & W & 0.98 & 0.97 & 0.94 & 0.96 & 0.97 & 0.89 & 0.96 & 0.96 & 0.81 & 0.75 \\
\hline \multirow{4}{*}{100} & $\mathrm{D}$ & 1.00 & 1.00 & 0.94 & 1.00 & 0.95 & 0.87 & 0.97 & 0.96 & 0.80 & \\
\hline & LHO & 1.00 & 1.00 & 0.91 & 0.99 & 0.95 & 0.94 & 0.98 & 0.94 & 0.89 & \\
\hline & RO & 0.98 & 0.98 & 0.97 & 0.97 & 0.96 & - & 0.97 & 0.98 & - & \\
\hline & $\mathrm{W}$ & 0.99 & 0.99 & 0.98 & 0.98 & 0.97 & 0.81 & 0.96 & 0.99 & - & \\
\hline
\end{tabular}

To further simplify the results and evaluate the physical outcome of the curve fitting, the variation of experimental parameters as a function of $t_{p}$ is shown for the following equations: (6d), (7), (9), and (10). Figure 10 shows the parameters for Eq. (6d); however, the other variants of Eq. (6) showed similar results. Note that all the following figures contain the estimated parameter values based on the additional terms in Eq. (16) which were derived from the data in Fig. 10. 

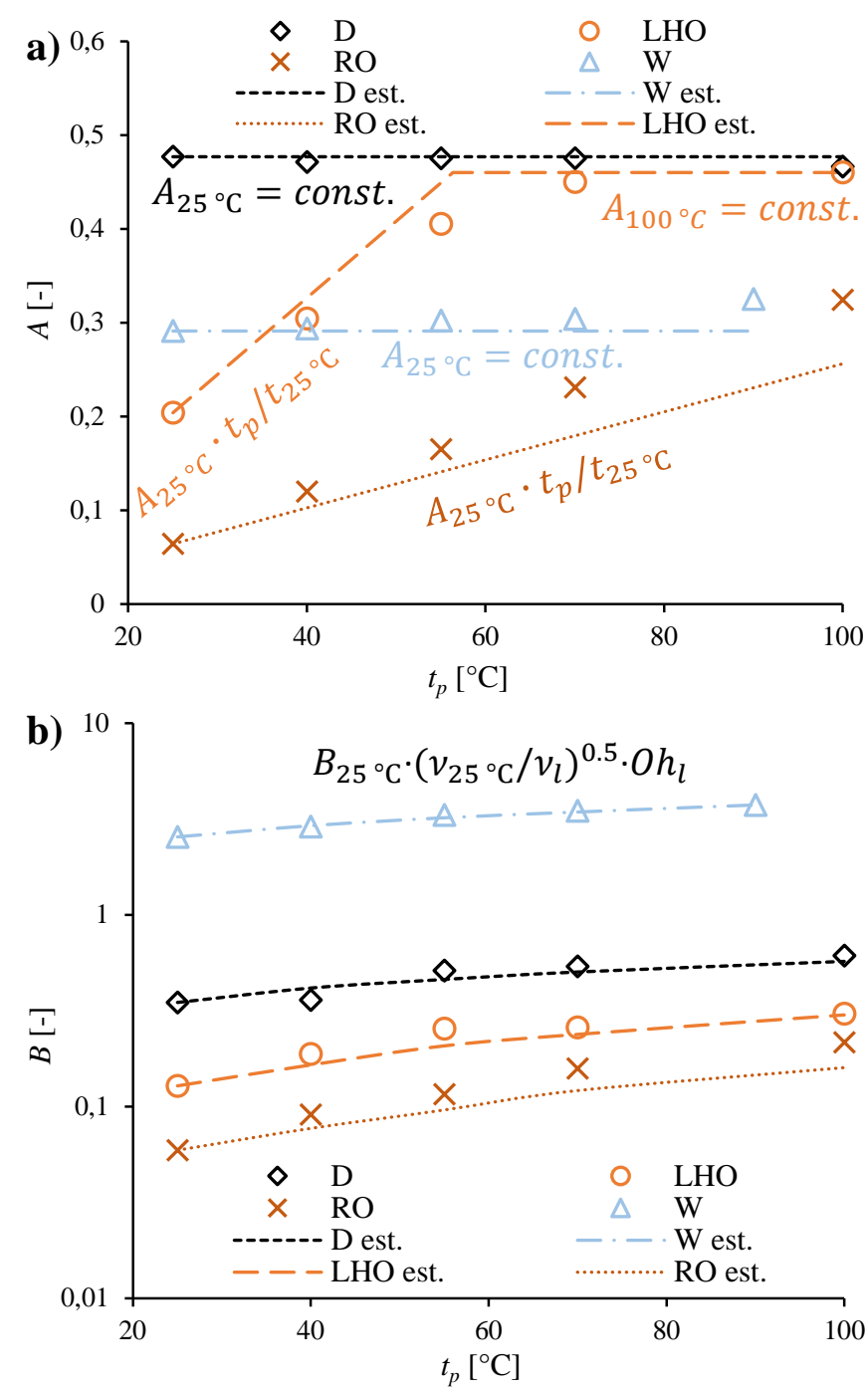

Fig. 10. Temperature dependence of $A$ and $B$ parameters of Eq. (6d) for all liquids, indicating the fitted trends for all liquids.

In Fig. 10a, the $A$ parameter value remained constant across the entire test range for the low viscosity D and W. However, LHO and RO showed a mostly linear temperature dependence. A transition point can be identified for $\mathrm{LHO}$ at $t_{p}=70^{\circ} \mathrm{C}$ when further liquid preheating does not affect $A$. Such a transitional behavior is already suggested by the flat trends of $\mathrm{D}$ and $\mathrm{W}$ while preheating notably affects RO in the investigated temperature range. Hence, a phenomenon, called the limiting viscosity can be introduced. It means that there is a viscosity value below which any further reduction in liquid viscosity does not affect the ISMD, even if the viscosity is further lowered, e.g. by increasing the liquid temperature. Therefore, this limit defines a target for the degree of liquid preheating in applications. The limiting viscosity is estimated as $v_{l, l i m}=$ 
$4.21 \mathrm{~mm}^{2} / \mathrm{s}$ in the present measurement configuration for LHO by using Eq. (6d) and is located at $56{ }^{\circ} \mathrm{C}$. This value of $v_{l, l i m}$ was derived assuming that $A$ was accurately calculated at $t_{p}=100$ ${ }^{\circ} \mathrm{C}$ and $t_{p}=25{ }^{\circ} \mathrm{C}$. Note that the error of $A_{25}{ }^{\circ} \mathrm{C}$ and $A_{100}{ }^{\circ} \mathrm{C}$ affects the determination of $v_{l, l i m}$, therefore, a focused investigation is necessary to reduce the uncertainty of the present estimation. Hence, a $t_{p}$-dependent factor can be introduced to the first term in Eq. (6). Concluding from this, an atomizer measurement at ambient temperature may be sufficient for predicting its ISMD at elevated $t_{p}$. However, the transitional behavior of LHO is not sharp and may require further investigations, even with other liquid types. The variation of $A$ in the case of RO has a slightly higher slope than that predicted, which might be further investigated focusing on various highviscosity liquids above $v_{l, l i m}$.

Figure 10b shows the variation of $B$ by which $O h$ is multiplied in Eq. (6d). Among the physical parameters of the liquids, a division of parameter $B$ with the temperature-dependent kinematic viscosity - without considering $v_{l, l i m}$ - was able to fit all trends in all cases. The above results are included in Eq. (16) which is an updated form of Eq. (6d):

$$
S M D=d_{0}(1+1 / A L R)\left[A_{t_{r}} \cdot\left\{\begin{array}{c}
t_{p} / t_{r}, \text { if } v_{l}>v_{l, \text { lim }} \\
1, \text { if } v_{l, t_{r}} \leq v_{l, l i m} \\
\left(t_{p} \text { at } v_{l, l i m}\right) / t_{r}, \text { if } v_{l} \leq v_{l, l i m} \\
+B_{t_{r}} \cdot\left(\frac{v_{l, t_{r}}}{v_{l}}\right)^{0.5} \cdot O h_{l}
\end{array}\right]\right.
$$

where $t_{r}$ is the reference temperature, which was $25{ }^{\circ} \mathrm{C}$ in the present case. If $t_{r}$ is a subscript, it reads as 'at the reference temperature.' Therefore, parameters $A\left(t_{p}\right)$ and $B\left(v_{l}\right)$ were corrected as detailed above to follow the effect of liquid preheating. Hence, they became univariate functions. Knowing this result may help combustion engineers to find an optimum degree of preheating for liquid fuels with high viscosity. An interesting outcome of Eq. (16) is that the temperature- 
dependent viscosity in $\mathrm{Oh}$ is divided by square root viscosity, meaning that this term has a square root viscosity in the nominator and a square root surface tension in the denominator. Following the parameter corrections introduced in Eq. (16), Figs. 11-13 include the estimated values for Eqs. (7), (9), and (10) based on the same freshly introduced terms.
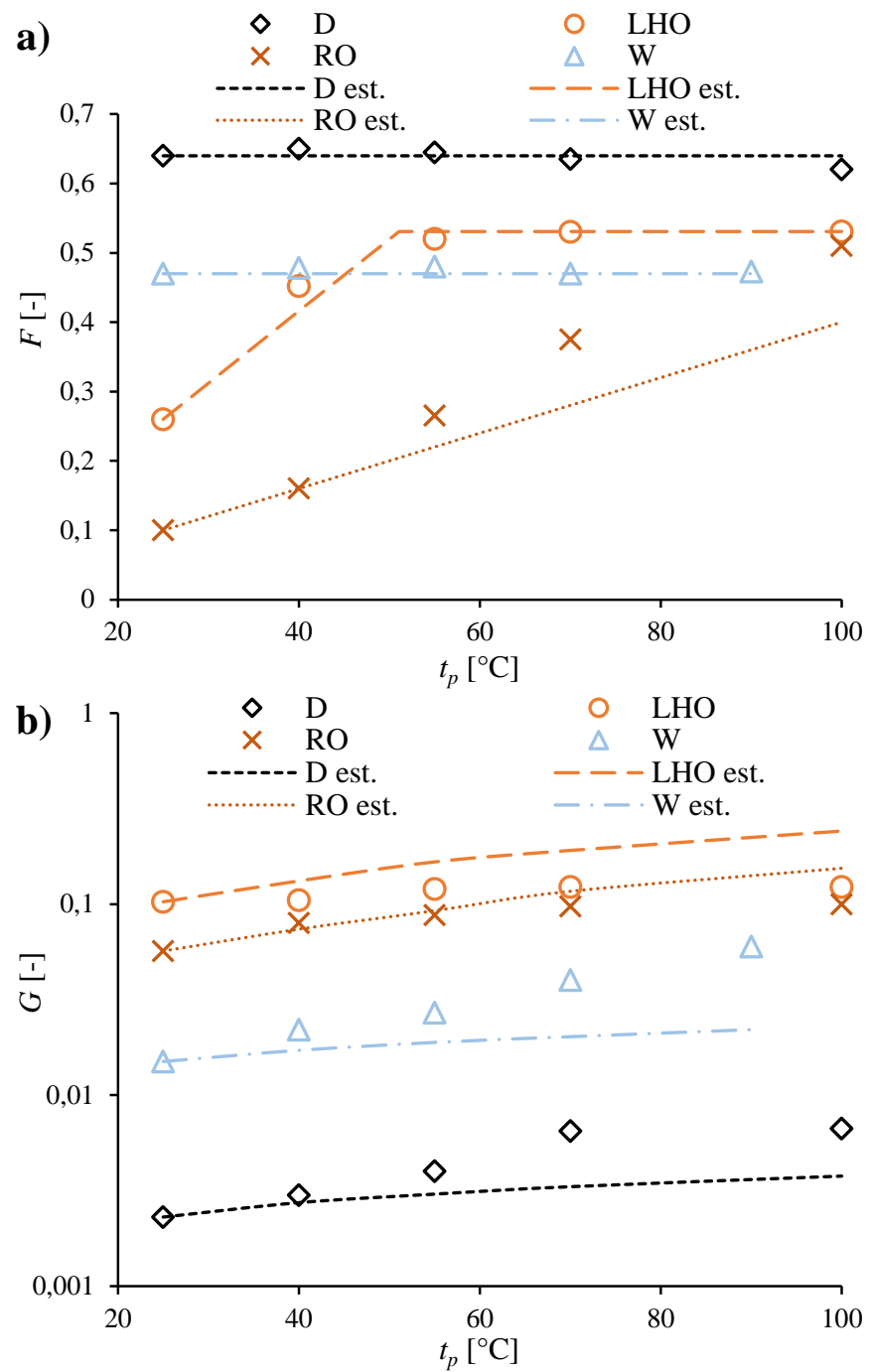

Fig. 11. Temperature dependence of $F$ and $G$ parameters of Eq. (7) for all liquids.

The estimated $v_{l, l i m}$ is $4.96 \mathrm{~mm}^{2} / \mathrm{s}$ in Eq. (7), which suggests that the viscosity of RO has slightly fallen below this value at $100{ }^{\circ} \mathrm{C}$, and no further increase of $F$ is expected, as shown in Fig. 11a. Since our investigations were limited to $100{ }^{\circ} \mathrm{C}$ for safety reasons, testing this finding requires higher $t_{p}$. Equation (7) has a manually modified dynamic part. Hence, parameter $G$ had to compensate for the distortion, resulting in a less accurate fit of the estimation based on 
parameter values at $25{ }^{\circ} \mathrm{C}$ by the same correction terms introduced in Eq. (16), as shown in Fig. 11b. Overall, Eq. (7) showed similar characteristics to Eq. (6d) with less accurate estimations due to the manually modified exponents in ref. [34]. Nevertheless, Eq. (7) still provides a fair estimation of $S M D$, which is a valuable conclusion since numerous researchers used this equation without the opportunity of experimentally validating this assumption [40,50-52].
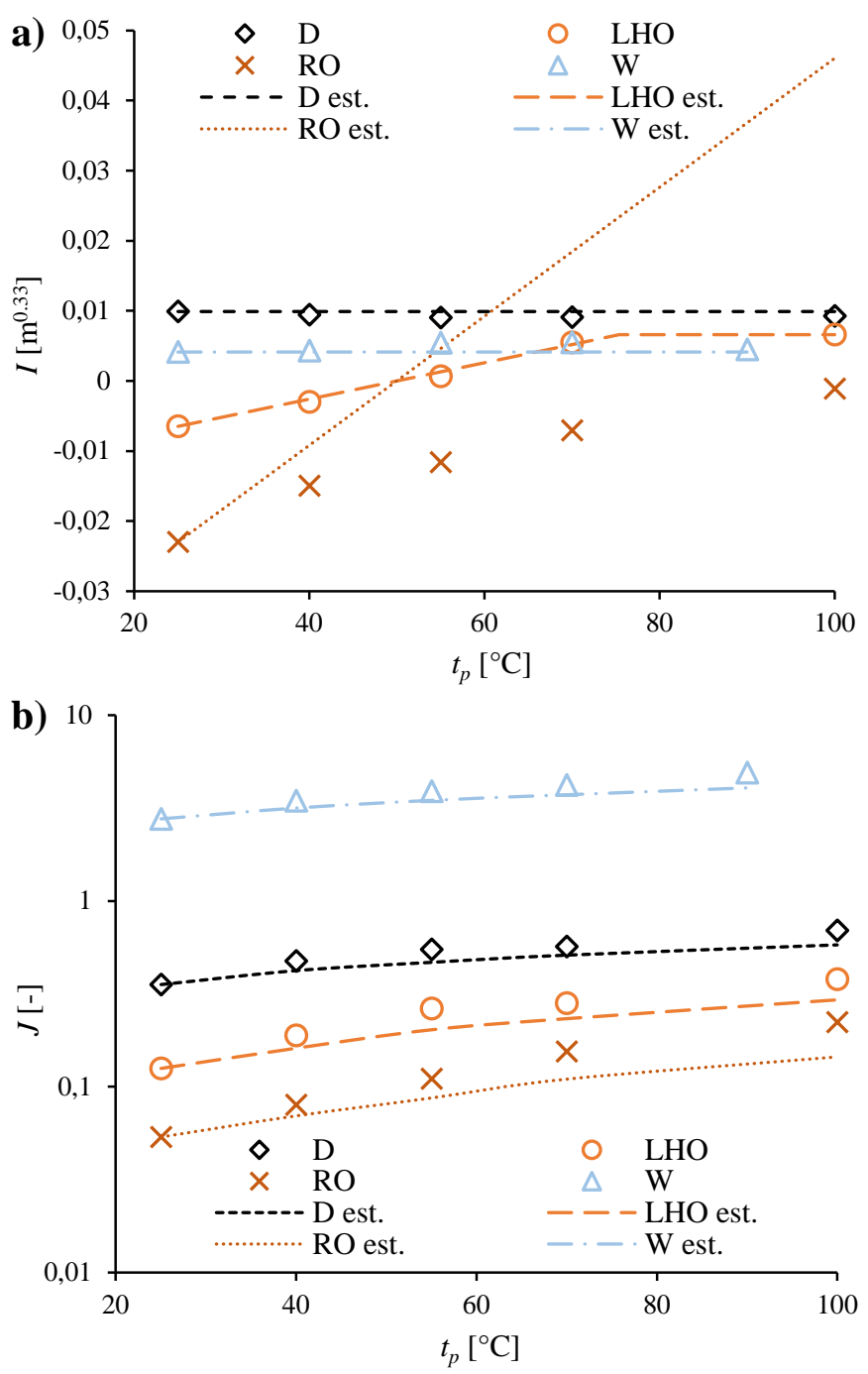

Fig. 12. Temperature dependence of $I$ and $J$ parameters of Eq. (9) for all liquids.

Figure 12a shows the drawbacks of Eq. (9) that suggests one to omit the use of this equation. Firstly, the parameter I was negative on multiple occasions for LHO and RO, which is mathematically appropriate and contributes to an excellent $R^{2}$ in Table 4. However, this is physically wrong. Secondly, $v_{l, l i m}$ is estimated as $2.78 \mathrm{~mm}^{2} / \mathrm{s}$, which is low, since the EN 
590:2014 standard allows for the viscosity of D as $v_{l}=2-4.5 \mathrm{~mm}^{2} / \mathrm{s}$, implying that even D should be preheated if it has a slightly higher viscosity but within the allowed range. This outcome is against the practice since no commonly used diesel engine contains a fuel preheater to achieve better atomization. Thirdly, the estimation of $I$ for RO failed. However, this equation was originally derived for low-viscosity liquids, and the estimations work nearly fine for the remaining three liquids. The parameter $J$ could be excellently corrected by the viscosity; hence, Fig. $12 \mathrm{~b}$ shows a satisfying result.
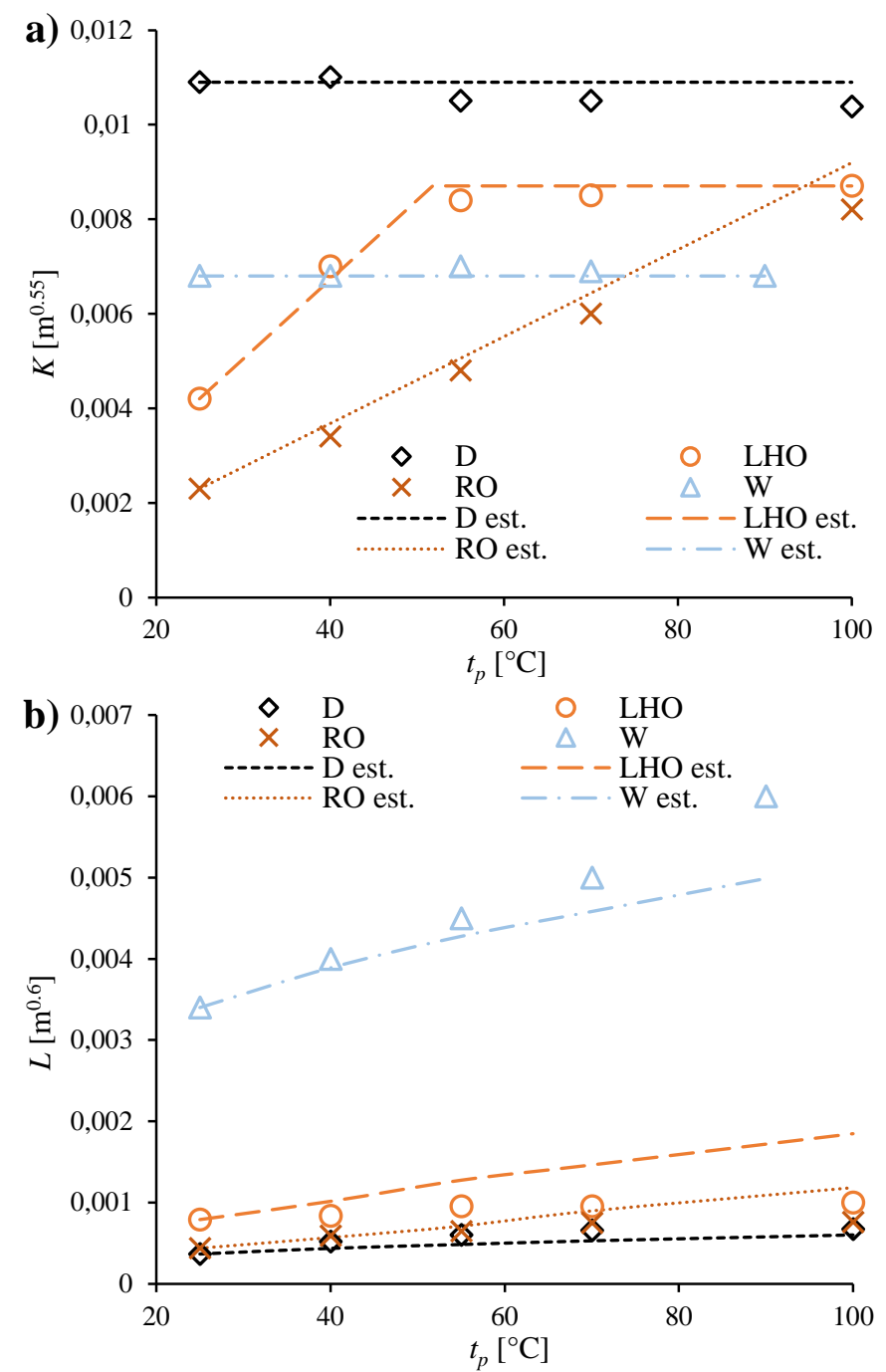

Fig. 13. Temperature dependence of $K$ and $L$ parameters of Eq. (10) for all liquids.

Equation (10) was derived for high-viscosity liquids. Therefore, parameter $K$ is estimated excellently even for RO as shown in Fig. 13a. $v_{l, l i m}=4.85 \mathrm{~mm}^{2} / \mathrm{s}$, which is similar to that of Eq. 
(7) and slightly higher than that of Eq. (6d). Figure 13b shows a good estimation for D and W while parameter $L$ is underestimated in the case of LHO and RO. It might be addressed to the slightly different exponents of Eq. (10) compared to Eq. (6d). Overall, in the dynamic term, Eq. (10) provides excellent fits; however, the material property term is less accurately estimated.

As for a summary, Eq. (6d) turned out to be the most accurate equation for SMD estimation which is followed by Eqs. (7) and (10). Even though the present analysis contained various formulae, it seems that the equation structure, suggested by Lefebvre in 1980 [10], seems to be the best one to date. Namely, SMD is governed by two terms, which should be summarized: the first depends on the reciprocal of square root We, while the other on $O h$.

\section{Conclusions}

The present paper discussed a high-velocity atmospheric atomization of four liquids: water (W), standard diesel oil (D), light heating oil (LHO), and crude rapeseed oil (RO) at various liquid preheating temperatures. The spray of the plain-jet airblast atomizer was non-intrusively investigated by a two-component Phase Doppler Anemometer. The velocity components, along with droplet sizes, were evaluated at a downstream distance, $z=60 \mathrm{~mm}$ from the atomizer nozzle. Then, nine empirical formulae were fitted to the measurement data to estimate the Sauter Mean Diameter, $S M D$, of the spray with liquid preheating. Since there is no known analytic way to estimate the $S M D$ of the spray of an airblast atomizer in the presently investigated conditions, the given empirical formulae were analyzed to better understand the background physics. Based on the results, the following conclusions were derived:

1. There is a limiting viscosity which significantly affects spray characteristics. It is supported by both the droplet size-velocity scatter plots and the fitted empirical 
formulae for estimating SMD. The viscosity limit in the current setup is estimated as $v_{l, l i m}=4.21 \mathrm{~mm}^{2} / \mathrm{s}$ based on Eq. (6d). Below this value, further preheating has no additional effect on the spray quality. This finding is in line with the facts that D can be excellently atomized without preheating while RO has to be introduced well above $100{ }^{\circ} \mathrm{C}$ into the combustion chamber to have a sufficiently fine spray for liquid fuel combustion. Among the investigated liquids, the limiting viscosity was found only in the case of LHO since only this liquid passes $v_{l, \text { lim }}$ from the investigated ones. Such a transitional characteristic was expected based on the results of D and W compared to RO.

2. The overshooting phenomenon was shown at the center of the spray and $z=60 \mathrm{~mm}$; namely, when the large droplets possess a higher velocity than the smaller ones and hence they accelerate the surrounding medium, the $y$ velocity component, $u_{y}$ of the larger droplets was negligible while $u_{z}$ was high. As the droplet size decreases, $u_{z}$ is reduced and $u_{y}$ increases. Since $u_{y}$ originates from the presence of turbulence, its mean value is zero.

3. SMD-estimating Eqs. (6d), (7), (9), and (10) showed the best fit by adjusting their experimental parameters via the Scatter Search MATLAB algorithm. However, the coefficient of the dynamic term of Eq. (9) started from a negative value, which is physically invalid. Since Eqs. (7) and (10) contain adjusted exponents, Eq. (6d) is the most widely applicable $S M D$-estimating equation to date for airblast atomization.

4. To estimate $S M D$ at elevated liquid temperatures, the parameters measured at ambient temperature have to be adjusted as follows. The coefficient of the Weber number should be multiplied by the desired temperature and divided by the reference temperature if the limiting viscosity is not reached. If reached, then the coefficient 
does not change any further and remains constant as a function of liquid preheating temperature. However, the Ohnesorge number should be multiplied by the square root of the ratio of the liquid viscosity at the reference temperature divided by the actual viscosity at the desired liquid preheating temperature.

The viability of the above findings is supported by the fact that the investigated formulae were developed for various atomizer designs and liquids; moreover, the present conditions regarding the atomizing air discharge velocity far exceeded the validity of the cited literature data. Liquid preheating was not examined by the researchers who experimentally derived the respective equations. However, the present research highlighted which $S M D$-estimating formulae are valid under the presently applied extreme conditions. In numbers, they are summarized in Table 3. The present researchers suggest modelers using Eq. (16) for estimating SMD of an airblast atomizer while supporting or debating the experimental results are highly welcome to further develop the models.

\section{Acknowledgments}

This work has been supported by the project №. GA18-15839S funded by the Czech Science Foundation and the project LO1202 NETME CENTRE PLUS with the financial support from the Ministry of Education, Youth and Sports of the Czech Republic under the "National Sustainability Program I" (funding of the Czech researchers), National Research, Development and Innovation Fund of Hungary, project №. FIEK 16-1-2016-0007 and OTKA-FK 124704, New National Excellence Program of the Ministry of Human Capacities project № ÚNKP-18-4-BME195, and the János Bolyai Research Scholarship of the Hungarian Academy of Sciences (funding of the Hungarian researchers). 


\section{Conflict of interest}

The authors declare that there is no conflict of interest.

\section{Appendix A. Measurement of temperature-dependent physical properties of liquids}

The following temperature-dependent physical properties were required to determine the atomization characteristics of the liquids: $\rho, \sigma$, and $v$. As for $\mathrm{W}$ and $\mathrm{D}$, they are well known in the literature. Besides the density, the other two parameters are rarely discussed for LHO and RO. It is known that the fatty acid composition of RO varies by the climate and the weather, besides cultivation methods [57-59]. Consequently, it was mandatory to measure the mentioned properties of the currently used samples. The investigation temperatures followed the $t_{p}: 25,40$, 55, 70, and $100^{\circ} \mathrm{C}$ while the highest temperature for $\mathrm{W}$ was $90^{\circ} \mathrm{C}$ to avoid boiling. Only $\sigma$ was measured at $75^{\circ} \mathrm{C}$ instead of $70{ }^{\circ} \mathrm{C}$. It is well-known that $\mathrm{W}$ and $\mathrm{D}$ are Newtonian liquids. Fasina and Colley [60] concluded that crude vegetable oils also exhibit Newtonian behavior, including RO. As for a light crude oil - which is more complex than LHO - it was proven by Ariffin et al. [61] that above 200 1/s shear rate it behaves as a Newtonian liquid in the temperature range of $20-90{ }^{\circ} \mathrm{C}$. The shear rate in the present case is estimated as $O(100.000) 1 / \mathrm{s}$.

Temperature-dependent densities were determined using a 10-ml 3.3 borosilicate glass pycnometer, which was put on a Sartorius L610 D type scale. The device was calibrated with known weights. The measurement results for all liquids were shown in Fig A.1. The combined expanded uncertainty at $95 \%$ level of significance was uniformly $4.8 \mathrm{~kg} / \mathrm{m}^{3}$. The results of W differ by $0.7 \%$ from the literature data at $90{ }^{\circ} \mathrm{C}$ while the measurement error was undetectable at

$25{ }^{\circ} \mathrm{C}$. This indirect way of measurement error estimation provides an independent basis of the 
accuracy of density measurements. All the measurements were repeated five times, and the density calculation was performed by their arithmetic average.

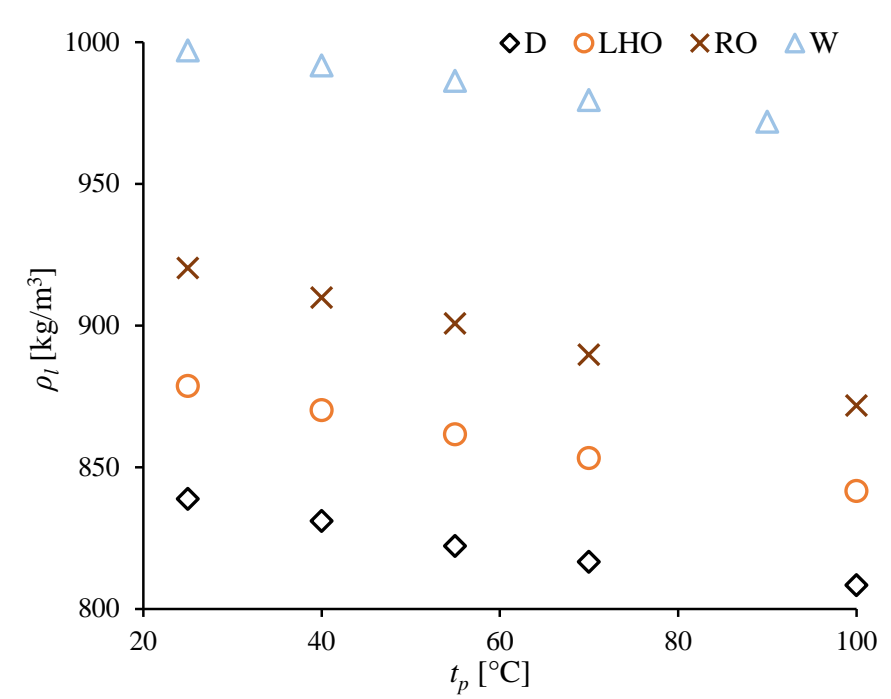

Fig. A.1. The measured density of the investigated liquids.

An Ostwald-type viscometer was used for determining the kinematic viscosities of the liquids. A large tempered tank filled with silicone oil hosted the viscometers. To have a homogeneous temperature distribution, a small pump continuously circulated the liquid. Since the instrument has a calibration constant which is valid at $25^{\circ} \mathrm{C}$, the measurement data of $\mathrm{W}$ was used to adjust the calibration constant for the other temperatures. Therefore, $\mathrm{W}$ has no error bars in Fig A.2, and its values follow the literature data. The error bars show the combined expanded uncertainties at a 95\% level of significance for the three other liquids. These measurements were repeated three times, and the viscosity calculation was performed by their arithmetic average. 


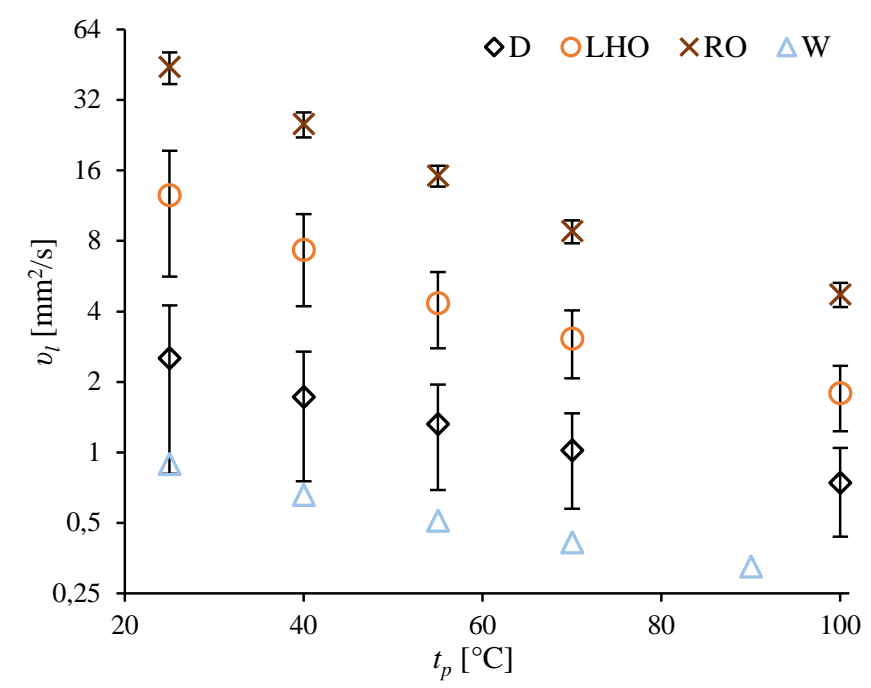

Fig A.2. The measured kinematic viscosity of the investigated liquids. Note the logarithmic scale on the ordinate.

As for surface tension measurement, the Wilhelmy plate method was used in the open atmosphere at various $t_{p}$ by using a double walled tempered pot. The heating medium was silicone oil to enable measurements at $100{ }^{\circ} \mathrm{C}$ for $\mathrm{D}, \mathrm{LHO}$, and RO. Calibration of the load cell was performed with known weights prior to installing the plate on the hook. The measurements were performed five times at each point, and their arithmetic average was presented in Fig. A.3. After heating the pot up from $25^{\circ} \mathrm{C}$ to $100{ }^{\circ} \mathrm{C}$, a check was performed at $75^{\circ} \mathrm{C}$ with three individual measurements for all liquids. The estimated uncertainty of the surface tension measurement at 95\% level of significance was uniformly $0.2 \mathrm{mN} / \mathrm{m}$.

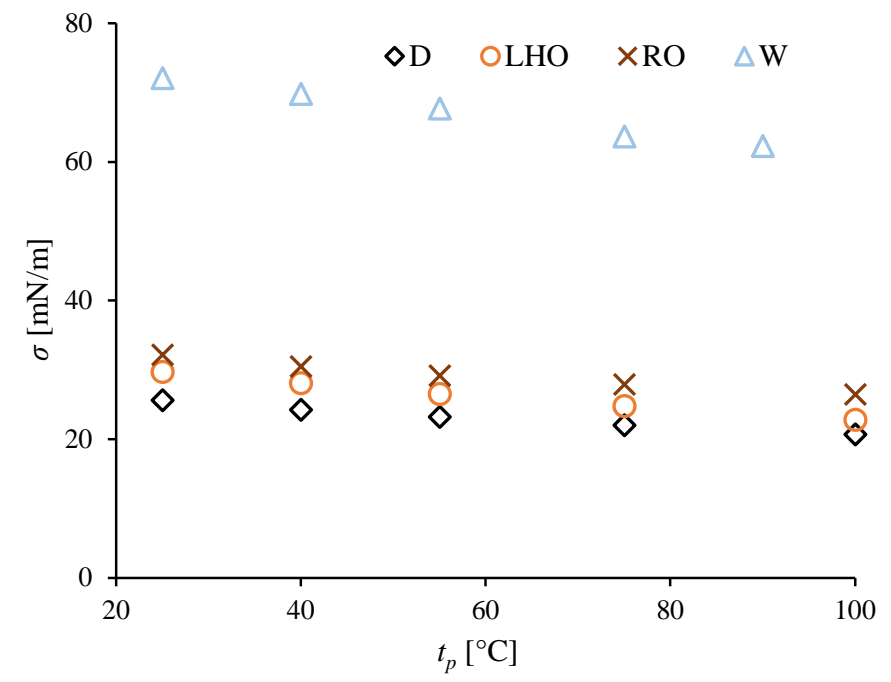

Fig. A.3. The measured surface tension of the investigated liquids. 
Temperature measurements had $<1{ }^{\circ} \mathrm{C}$ uncertainty. All the measurement data was in good agreement with the literature data where a comparison was possible $[15,62-64]$. In the case of W, IAPWS-IF97 was used as an internationally accepted reference for the properties of $\mathrm{H}_{2} \mathrm{O}$. Nevertheless, none of the required temperature-dependent data for LHO was found in the public literature.

\section{References}

[1] S. Poozesh, K. Lu, P.J. Marsac, On the particle formation in spray drying process for bio-pharmaceutical applications: Interrogating a new model via computational fluid dynamics, Int. J. Heat Mass Transf. 122 (2018) 863-876. doi:10.1016/j.ijheatmasstransfer.2018.02.043.

[2] A. Panda, A.R. Pati, S. Pradhan, B. Saha, A. Kumar, S.S. Mohapatra, High mass flux air atomized spray with subcooled water: A novel methodology to enhance the heat transfer rate in film boiling regime, Int. J. Heat Mass Transf. 120 (2018) 1287-1304. doi:10.1016/j.ijheatmasstransfer.2017.12.051.

[3] N.A. Chigier, The atomization and burning of liquid fuel sprays, Prog. Energy Combust. Sci. 2 (1976) 97-114. doi:10.1016/0360-1285(76)90019-8.

[4] M.R. Saavedra M., C.H. Cristiano, F.G. Francisco, Sustainable and renewable energy supply chain: A system dynamics overview, Renew. Sustain. Energy Rev. 82 (2018) 247-259. doi:10.1016/j.rser.2017.09.033.

[5] A.N. Oumer, M.M. Hasan, A.T. Baheta, R. Mamat, A.A. Abdullah, Bio-based liquid fuels as a source of renewable energy: A review, Renew. Sustain. Energy Rev. 88 (2018) 82-98. doi:10.1016/j.rser.2018.02.022.

[6] V. Józsa, A. Kun-Balog, Stability and emission analysis of crude rapeseed oil combustion, Fuel Process. Technol. 156 (2017) 204-210. doi:10.1016/j.fuproc.2016.11.004.

[7] A. Kun-Balog, K. Sztankó, V. Józsa, Pollutant emission of gaseous and liquid aqueous bioethanol combustion in swirl burners, Energy Convers. Manag. 149 (2017) 896-903. doi:10.1016/j.enconman.2017.03.064.

[8] H.-G. Chen, Y.-H.P. Zhang, New biorefineries and sustainable agriculture: Increased food, biofuels, and ecosystem security, Renew. Sustain. Energy Rev. 47 (2015) 117-132. doi:10.1016/j.rser.2015.02.048.

[9] E. Cséfalvay, G.R. Akien, L. Qi, I.T. Horváth, Definition and application of ethanol equivalent: Sustainability performance metrics for biomass conversion to carbon-based fuels and chemicals, Catal. Today. 239 (2015) 50-55. doi:10.1016/j.cattod.2014.02.006.

[10] A.H. Lefebvre, Airblast atomization, Prog. Energy Combust. Sci. 6 (1980) 233-261. doi:10.1016/0360-1285(80)90017-9.

[11] A.H. Lefebvre, V.G. McDonell, Atomization and Sprays, Second, CRC Press, Boca Raton, FL, 2017.

[12] A.A. Rizkalla, A.H. Lefebvre, The influence of air and liquid properties on airblast atomization, J. Fluids Eng. 97 (1975) 316-320.

[13] C.M. Varga, J.C. Lasheras, E.J. Hopfinger, Initial breakup of a small-diameter liquid jet 
by a high-speed gas stream, J. Fluid Mech. 497 (2003) 405-434.

doi:10.1017/S0022112003006724.

[14] A. Urbán, M. Zaremba, M. Malý, V. Józsa, J. Jedelský, Droplet dynamics and size characterization of high-velocity airblast atomization, Int. J. Multiph. Flow. 95 (2017) 111. doi:10.1016/j.ijmultiphaseflow.2017.02.001.

[15] B. Esteban, J.-R. Riba, G. Baquero, A. Rius, R. Puig, Temperature dependence of density and viscosity of vegetable oils, Biomass and Bioenergy. 42 (2012) 164-171. doi:10.1016/j.biombioe.2012.03.007.

[16] X.F. Wang, A.H. Lefebvre, Influence of fuel temperature on atomization performance of pressure-swirl atomizers, J. Propuls. Power. 4 (1988) 222-227. doi:10.2514/3.23052.

[17] P.R. Shah, A. Ganesh, Study the influence of pre-heating on atomization of straight vegetable oil through Ohnesorge number and Sauter mean diameter, J. Energy Inst. (2017) 1-7. doi:10.1016/j.joei.2017.10.006.

[18] R. Hanna, A. Zoughaib, Atomization of high viscosity liquids through hydraulic atomizers designed for water atomization, Exp. Therm. Fluid Sci. 85 (2017) 140-153. doi:10.1016/j.expthermflusci.2017.03.004.

[19] S.H. Park, H.J. Kim, H.K. Suh, C.S. Lee, Experimental and numerical analysis of sprayatomization characteristics of biodiesel fuel in various fuel and ambient temperatures conditions, Int. J. Heat Fluid Flow. 30 (2009) 960-970.

doi:10.1016/j.ijheatfluidflow.2009.04.003.

[20] M.A. Al-Shudeifat, A.B. Donaldson, Combustion of waste trap grease oil in gas turbine generator, Fuel. 89 (2010) 549-553. doi:10.1016/j.fuel.2009.10.016.

[21] T. Seljak, S.R. Oprešnik, M. Kunaver, T. Katrašnik, Effects of primary air temperature on emissions of a gas turbine fired by liquefied spruce wood, Biomass and Bioenergy. 71 (2014) 394-407. doi:10.1016/j.biombioe.2014.09.016.

[22] T. Seljak, T. Katrašnik, Designing the microturbine engine for waste-derived fuels, Waste Manag. 47 (2016) 299-310. doi:10.1016/j.wasman.2015.06.004.

[23] A.H. Lefebvre, D.R. Ballal, Gas turbine combustion, third, CRC Press, Boca Raton, 2010.

[24] Q.P. Zheng, A.K. Jasuja, A.H. Lefebvre, Influence of air and fuel flows on gas turbine sprays at high pressures, Symp. Combust. 26 (1996) 2757-2762. doi:10.1016/S00820784(96)80113-5.

[25] S. Nukiyama, Y. Tanasawa, Experiments on the atomization of liquids in an airstream, Trans. Japan Soc. Mech. Eng. 5 (1939) 68-75.

[26] A. Kourmatzis, P.X. Pham, A.R. Masri, Air assisted atomization and spray density characterization of ethanol and a range of biodiesels, Fuel. 108 (2013) 758-770. doi:10.1016/j.fuel.2013.01.069.

[27] L. Durdina, J. Jedelsky, M. Jicha, Investigation and comparison of spray characteristics of pressure-swirl atomizers for a small-sized aircraft turbine engine, Int. J. Heat Mass Transf. 78 (2014) 892-900. doi:10.1016/j.ijheatmasstransfer.2014.07.066.

[28] G. Chaussonnet, O. Vermorel, E. Riber, B. Cuenot, A new phenomenological model to predict drop size distribution in Large-Eddy Simulations of airblast atomizers, Int. J. Multiph. Flow. 80 (2016) 29-42. doi:10.1016/j.ijmultiphaseflow.2015.10.014.

[29] X. Jiang, G.A. Siamas, K. Jagus, T.G. Karayiannis, Physical modelling and advanced simulations of gas-liquid two-phase jet flows in atomization and sprays, Prog. Energy Combust. Sci. 36 (2010) 131-167. doi:10.1016/j.pecs.2009.09.002.

[30] M. Behzad, N. Ashgriz, B.W. Karney, Surface breakup of a non-turbulent liquid jet injected into a high pressure gaseous crossflow, Int. J. Multiph. Flow. 80 (2016) 100- 
117. doi:10.1016/j.ijmultiphaseflow.2015.11.007.

[31] N. Ashgriz, Hand book of atomization and sprays, Springer Science \& Business Media, LLC, 2011. doi:10.1007/978-1-4419-7264-4.

[32] ANSYS Inc., ANSYS Fluent Theory Guide, (2018).

[33] Arthur H. Lefebvre, Airblast atomization, Prog. Energy Combust. Sci. 6 (1980) 233261. doi:https://doi.org/10.1016/0360-1285(80)90017-9.

[34] N.K. Rizk, A.H. Lefebvre, Spray Characteristics of Plain-Jet Airblast Atomizers, J. Eng. Gas Turbines Power. 106 (1984) 634-638. http://dx.doi.org/10.1115/1.3239617.

[35] C.T. Chong, Combustion Characteristics of Alternative Liquid Fuels, University of Cambridge, 2011.

[36] A. Mansour, N. Chigier, Air-blast atomization of non-Newtonian liquids, J. Nonnewton. Fluid Mech. 58 (1995) 161-194. doi:10.1016/0377-0257(95)01356-Z.

[37] C.T. Chong, S. Hochgreb, Effect of Atomizing Air Flow on Spray Atomization of an Internal-Mix Twin-Fluid Atomizer, At. Sprays. 25 (2015) 657-673. doi:10.1615/AtomizSpr.2015011361.

[38] H. V. Panchasara, B.M. Simmons, A.K. Agrawal, S.K. Spear, D.T. Daly, Combustion Performance of Biodiesel and Diesel-Vegetable Oil Blends in a Simulated Gas Turbine Burner, J. Eng. Gas Turbines Power. 131 (2009) 031503. doi:10.1115/1.2982137.

[39] F.Z.M. Batarseh, Spray generated by an airblast atomizer: atomization , propagation and aerodynamic instability, 2008.

[40] C.D. Bolszo, Investigation of Atomization, Mixing and Pollutant Emissions for a Microturbine Engine, UCI Undergrad. Res. J. VIII (2005) 13-22.

[41] G.E. Lorenzetto, A.H. Lefebvre, Measurements of Drop Size on a Plain-Jet Airblast Atomizer, AIAA J. 15 (1977) 1006-1010. doi:10.2514/3.60742.

[42] A.K. Jasuja, Airblast Atomization of Alternative Liquid Petroleum Fuels under High Pressure Conditions, J. Eng. Power. 103 (1982) 514. doi:10.1115/1.3230751.

[43] A.K. Jasuja, Atomization of Crude and Residual Fuel Oils, J. Eng. Power. 101 (1979) 250. doi:10.1115/1.3446480.

[44] S.C. Tsai, B. Viers, Airblast atomization of viscous liquids, Fuel. 69 (1990) 1412-1419. doi:10.1016/0016-2361(90)90123-8.

[45] B.K. Park, J.S. Lee, K.D. Kihm, Comparative study of twin-fluid atomization using sonic or supersonic gas jets, At. Sprays. (1996).

[46] K.D. Kihm, N. Chigier, Effect of Shock Waves on Liquid Atomization of a TwoDimensional Airblast Atomizer, At. Sprays. 1 (1991) 113-136.

[47] J. Jedelsky, M. Jicha, Energy considerations in spraying process of a spill-return pressure-swirl atomizer, Appl. Energy. 132 (2014) 485-495. doi:10.1016/j.apenergy.2014.07.042.

[48] Z. Ugray, L. Lasdon, J. Plummer, F. Glover, Scatter Search and Local NLP Solvers : A Multistart Framework for Global Optimization, Inf. Syst. 19 (2006) 328-340. doi:10.1287/ijoc.1060.0175.

[49] V. Józsa, D. Csemány, Evaporation of renewable fuels in a lean premixed prevaporized burner, Period. Polytech. Mech. Eng. 60 (2016) 82-88. doi:10.3311/PPme.8564.

[50] A. Kun-Balog, K. Sztankó, Reduction of pollutant emissions from a rapeseed oil fired micro gas turbine burner, Fuel Process. Technol. 134 (2015) 352-359. doi:10.1016/j.fuproc.2015.02.017.

[51] S. Nakamura, V. McDonell, S. Samuelsen, The Effect of Liquid-Fuel Preparation on Gas Turbine Emissions, J. Eng. Gas Turbines Power. 130 (2008) 021506. doi:10.1115/1.2771564. 
[52] M. Prussi, D. Chiaramonti, G. Riccio, F. Martelli, L. Pari, Straight vegetable oil use in Micro-Gas Turbines: System adaptation and testing, Appl. Energy. 89 (2012) 287-295. doi:10.1016/j.apenergy.2011.07.031.

[53] Dantec Dynamics, Integrated solutions in Particle Dynamics Analysis, Nov. Instruments. (2011) 2-4.

[54] V. Józsa, A. Kun-balog, Spectroscopic analysis of crude rapeseed oil flame, Fuel Process. Technol. 139 (2015) 61-66. doi:10.1016/j.fuproc.2015.08.011.

[55] J.C. Lasheras, E. Villermaux, E.J. Hopfinger, Break-up and atomization of a round water jet by a high-speed annular air jet, J. Fluid Mech. 357 (1998) 351-379. doi:10.1017/S0022112097008070.

[56] A.P. Kulkarni, D. Deshmukh, Spatial drop-sizing in airblast atomization-An experimental study, At. Sprays. 27 (2017) 949-961. doi:10.1615/AtomizSpr.2017021428.

[57] E.A. Melo-Espinosa, Y. Sánchez-Borroto, M. Errasti, R. Piloto-Rodríguez, R. Sierens, J. Roger-Riba, A. Christopher-Hansen, Surface Tension Prediction of Vegetable Oils Using Artificial Neural Networks and Multiple Linear Regression, Energy Procedia. 57 (2014) 886-895. doi:10.1016/j.egypro.2014.10.298.

[58] M. Gauthier, D. Pellet, C. Monney, J.M. Herrera, M. Rougier, A. Baux, Fatty acids composition of oilseed rape genotypes as affected by solar radiation and temperature, $\mathrm{F}$. Crop. Res. 212 (2017) 165-174. doi:10.1016/j.fcr.2017.07.013.

[59] E.G. Giakoumis, Analysis of 22 vegetable oils' physico-chemical properties and fatty acid composition on a statistical basis, and correlation with the degree of unsaturation, Renew. Energy. 126 (2018) 403-419. doi:10.1016/j.renene.2018.03.057.

[60] O.O. Fasina, Z. Colley, Viscosity and Specific Heat of Vegetable Oils as a Function of Temperature: 35C to 180C, Int. J. Food Prop. 11 (2008) 738-746. doi:10.1080/10942910701586273.

[61] T.S.T. Ariffin, E. Yahya, H. Husin, The rheology of light crude oil and water-in-oilemulsion, Procedia Eng. 148 (2016) 1149-1155. doi:10.1016/j.proeng.2016.06.614.

[62] H. Noureddini, B.C. Teoh, L.D. Clements, Viscosities of Vegetable Oils and Fatty Acids, J. Am. Oil Chem. Soc. 69 (1992) 1189-1190.

[63] J. Dechoz, C. Rozé, Surface tension measurement of fuels and alkanes at high pressure under different atmospheres, Appl. Surf. Sci. 229 (2004) 175-182. doi:10.1016/j.apsusc.2004.01.057.

[64] B. Esteban, J.-R. Riba, G. Baquero, R. Puig, A. Rius, Characterization of the surface tension of vegetable oils to be used as fuel in diesel engines, Fuel. 102 (2012) 231-238. doi:10.1016/j.fuel.2012.07.042. 